\title{
Thermodynamic modelling of solid solutions
}

\author{
JiBAMITRA GANGULY \\ Department of Geosciences, University of Arizona, \\ Tucson, AZ 85721, USA; \\ e-mail: ganguly@geo.arizona.edu
}

\section{Introduction}

One of the major goals of petrology is to retrieve values of the intensive parameters, such as pressure $(P)$, temperature $(T)$ and fluid composition, under which the major mineralogical properties of a rock were established, along with the time scales of evolution of the mineralogical properties. The basic approach in the retrieval of the intensive properties involves comparison of the mineralogical assemblages and the mineral compositions of the rock with the phase equilibrium constraints. The latter are calculated from the internally consistent thermochemical properties of the stoichiometric end members or determined in the laboratory on relatively simple systems, usually involving only the end-member phases, and then corrected for the effects of the compositional departures as observed in a specific natural assemblage. In addition, many mineral pairs (e.g. garnet and biotite) respond to changes of $P-T$ conditions, especially temperature, by continuous ion exchange reactions, and thus register the $P-T$ condition or $P-T$ history of the rock in their compositions. The ionexchange reactions are also calibrated in the laboratory on relatively simple systems, but require corrections for the effects of additional components that enter into solid solution in the minerals in natural environments. The corrections for the compositional effects rely critically on the thermodynamic mixing properties of the components in the mineral solid solutions and fluid phase which are involved in a specific reaction (e.g. Ganguly \& Saxena, 1987). There has, thus, been a sustained effort over the last few decades on the determination of thermodynamic mixing properties of phases in geologically important systems.

In this review, I will summarise the general concepts of thermodynamic solution theory and a number of macroscopic models that have been used in the treatment of experimental data on mineral solid solutions. Some of the solution models were originally developed for polymer and liquid solutions, but are also applicable to oxide and solid solutions. For reasons of both time and space, I have not included orderdisorder theory specifically, although some aspects of the thermodynamics of minerals showing such behaviour may also be treated within the framework of the models discussed in this review, as will be pointed out in the appropriate sections. I have assumed that the reader has a working knowledge of thermodynamics, including the fundamentals of thermodynamic solution theory. Thus, only a brief discussion of the 
solution theory has been included in this review in the spirit of recapitulation and reemphasis of some of the important points. The presentation of the topics follows a systematic order in that the concepts presented in a particular section builds on what has been presented in the preceding sections. The primary aim here has been to convey the general physical ideas and thermodynamic concepts underlying various mixing models. Consequently, in many cases the reader will have to consult the appropriate references cited to find the equations that are needed for the use of a specific model, or derive these equations following the methods that I have outlined.

To conform to the modern usage of terminologies (e.g. Hillert, 1998), and also for the sake of brevity, Gibbs free energy will be referred to as Gibbs energy and a partial molar quantity as simply a partial quantity. In the following list of symbols, the old terminologies are shown within the parentheses.

\section{Selected list of symbols and abbreviations:}

$a_{i}$ and $a_{i}^{0} \quad$ activity of the component $i$ in a solution and in the pure state, respectively $D \quad$ diffusion coefficient

$G$ and $G_{\mathrm{m}} \quad$ total and molar Gibbs (free) energy of a solution, respectively

$G_{i} \quad$ partial (molar) Gibbs (free) energy of a component $i$

$\Delta G^{0}(\mathrm{rec}) \quad$ the standard state Gibbs (free) energy change of a reciprocal reaction

$L$

$n_{i}$ and $N \quad$ number of moles of the component $i$ and the total number of moles of components in a solution, respectively

$Q \quad$ activation energy of diffusion

$q_{i} \quad$ contact factor of the component $i$ in the quasi-chemical formulation

$X_{i} \quad$ mole fraction of a macroscopic component $i$

$X_{i j} \quad$ a binary mole fraction defined by the normal projection of a

multicomponent composition onto the binary join $i-j$

$X_{i}^{*} \quad$ a compositional function used to express the activity of a component $i$

$X \quad$ composition

$\chi_{j}$

$\chi_{j i}$

$\Delta Y_{\mathrm{m}}^{\mathrm{xs}}$

$\Delta Y_{\mathrm{m}}^{\operatorname{mix}}$

$Y_{i}^{*}$ and $Y_{i}^{0}$

$Z$

atomic fraction of $j$ within a crystallographic site (usually specified by a

left superscript, e.g. ${ }^{\mathrm{I}} \chi_{j}$ )

local mole fraction of a component $j$ around a central component $i$

an excess molar property of a solution

a molar property of mixing of a solution

a property at the standard state and at the pure state, respectively, of the

component $i$

nearest neighbour coordination number of a central atom within a sublattice

$\gamma_{i}$ activity coefficient of a component $i$ related to the compositional function $X_{i}^{\bullet}$, i.e. $\gamma_{i}^{\bullet}=a_{i} / \gamma_{i}^{\bullet}$

$\gamma_{i}$ and $\gamma(i) \quad$ activity coefficient of the component $i$

$\mu_{i}$ and $\mu(i) \quad$ chemical potential of the component $i$

$\sigma$ standard deviation. 
$\phi_{i} \quad$ site fraction of the component $i$ in a polymer solution

$\xi_{i} \quad$ local volume fraction of the component $i$

$\mathrm{Ab} \quad$ albite $\left(\mathrm{NaAlSi}_{3} \mathrm{O}_{8}\right)$

An anorthite $\left(\mathrm{CaAl}_{2} \mathrm{Si}_{2} \mathrm{O}_{8}\right)$

CaTs calcium-Tschermak pyroxene $\left(\mathrm{Ca}^{\mathrm{VI}} \mathrm{Al}^{\mathrm{IV}} \mathrm{AlSiO}_{6}\right]$

Di diopside $\left(\mathrm{CaMgSi}_{2} \mathrm{O}_{6}\right)$

En enstatite $\left(\mathrm{MgSiO}_{3}\right)$

Grs grossular $\left(\mathrm{Ca}_{3} \mathrm{Al}_{2} \mathrm{Si}_{3} \mathrm{O}_{12}\right)$

$\mathrm{Kfs} \quad$ potassium feldspar $\left(\mathrm{KAlSi}_{3} \mathrm{O}_{8}\right)$

$\mathrm{Ol}$ olivine

Prp pyrope $\left(\mathrm{Mg}_{3} \mathrm{Al}_{2} \mathrm{Si}_{3} \mathrm{O}_{12}\right)$

Spl spinel

DQF Darken's quadratic formulation

NRTL non random two liquid model

QC quasi-chemical model

UNIQUAC universal quasi-chemical model

\section{Thermodynamics of solutions: a brief outline}

In this section, I will present a brief summary of the thermodynamic formalisms relating to the properties of a solution so that the subsequent sections can be followed in a selfcontained manner. For more detailed discussions, the reader is referred to Ganguly \& Saxena (1987) and Hillert (1998).

\section{Gibbs-Duhem relation and partial quantities}

At a constant $P-T$ condition, the Gibbs energy $(G)$ of a solution is given by

$$
G=\sum n_{i} \mu_{i}
$$

where $n_{i}$ and $\mu_{i}$ are, respectively, the number of moles and chemical potential of the component $i$. Thus,

$$
d G=\sum n_{i} d \mu_{i}+\sum \mu_{i} d n_{i}
$$

Now, since we also have

$$
d G=-S d T+V d P+\sum \mu_{i} d n_{i},
$$

where $S$ and $V$ are the total entropy and total volume of the solution, respectively, we obtain, on equating, at constant $P-T$ condition, the right hand terms of the last two equations

$$
\sum n_{i} d \mu_{i}=0
$$

or

$$
\sum X_{i} d \mu_{i}=0
$$


where $X_{i}$ is the mole fraction of the component $i$. This expression, which is known as the Gibbs-Duhem relation, provides a relationship among the change of chemical potentials of the components in a solution at constant $P-T$ condition.

The partial property, $Y_{i}\left(\right.$ e.g. partial volume $V_{i}$ ), of a component in a solution at a fixed composition $(X)$ is the rate of change of the corresponding total property of the solution, $Y($ e.g. total volume, $V$ ), with respect to the change of the number of moles of that component when $P, T$ and the number of moles of all other components are held constant. The chemical potential, $\mu_{i}$, of a component at a fixed $P-T$ condition is equivalent to its partial Gibbs energy, $G_{i}$. However, using Equations 1 and $4 \mathrm{~b}$ (i.e. the Gibbs-Duhem relation), and some manipulations (e.g. Darken \& Gurry, 1953), the chemical potential of a component in a binary solution can be expressed in terms of the molar Gibbs energy, $G_{\mathrm{m}}$, as

$$
\mu_{i} \equiv G_{i}=G_{\mathrm{m}}+\left(1-X_{i}\right)\left(\frac{\partial G_{\mathrm{m}}}{\partial X_{i}}\right)_{P, T} .
$$

A relation analogous to Equation 5 also holds for a multicomponent solution if the derivative of $G_{\mathrm{m}}$ with respect to the $X_{i}$ is taken at constant $P, T$ and constant relative amounts of all components other than $i$, i.e. at constant $X_{j}: X_{k}: X_{l}: \ldots$ (Darken, 1950). This multicomponent expression is often referred to as the Darken equation, and has been applied by Sack \& Loucks (1985) and Ghiorso (1990) to the problems of multicomponent mineral solid solutions.

An alternative to the Darken equation for the derivation of partial properties in a multicomponent solution is due to Hillert (e.g. Hillert 1998), which is as follows

$$
\mu_{i}=G_{\mathrm{m}}+\left(1-X_{i}\right) \frac{\partial G_{\mathrm{m}}}{\partial X_{i}}-\sum_{k \neq i} \frac{\partial G_{\mathrm{m}}}{\partial X_{k}}
$$

or, collecting the first derivative term within the summation,

$$
\mu_{i}=G_{\mathrm{m}}+\frac{\partial G_{\mathrm{m}}}{\partial X_{i}}-\sum_{k} \frac{\partial G_{\mathrm{m}}}{\partial X_{k}} .
$$

Here the derivative terms with respect to the atomic fraction of a component are taken at either constant atomic fractions of all other components, or of all other $(n-2)$ independent components in an $n$ component system. The equivalence between the two procedures follows from the fact that if one component, say the $n$-th component, is chosen to be the dependent component, then

$$
\left(\frac{\partial Y}{\partial X_{i}}\right)_{i+n, j^{\prime}}=\left(\frac{\partial Y}{\partial X_{i}}\right)_{j \neq i}-\left(\frac{\partial Y}{\partial X_{n}}\right)_{j \neq n},
$$

where the subscripts outside the parentheses refer to the atomic fractions of the specified components $\left(i . e . i \equiv X_{i}\right.$ ), and $j^{\prime}$ refers to the atomic fractions of all other components 
except those of $i$ and $n$. Here $Y$ is any property which is a function of the $X_{i}$-s. For the derivation of partial properties in a multicomponent system, Hillert's expression is simpler to deal with than Darken's (and is incorporated in the commercial Thermo-Calc program for phase equilibrium calculations: http://www.thermocalc.se).

Similar expressions also hold for other partial quantities. Thus, in general, we can replace $\mu_{i}$ and $G_{\mathrm{m}}$ by the generalised partial property, $Y_{i}$, and the generalised molar property, $Y_{\mathrm{m}}$, respectively.

\section{Activity and standard state}

The chemical potential of a component $(i)$ at a given pressure, temperature and composition of the solution is expressed as

$$
\begin{aligned}
\mu_{i}(P, T, X) & =\mu_{i}^{*}\left(P^{*}, T, X^{*}\right)+R T \ln a_{i} \\
& =\mu_{i}^{*}\left(P^{*}, T, X^{*}\right)+R T \ln \left(X_{i}^{*} \gamma_{i}^{*}\right) .
\end{aligned}
$$

Here $\mu_{i}^{*}\left(P^{*}, T, X^{*}\right)$ is the chemical potential of the component $i$ at the temperature of interest and at some reference pressure $\left(P^{*}\right)$ and composition $\left(X^{*}\right)$ of the solution, $a_{i}$ is the activity of the component $i$ in solution at the specified $P-T-X$ condition, $X_{i}^{\star}$ is a conveniently chosen compositional function, and $\gamma_{i}^{*}$ is the corresponding activity coefficient. $X_{i}^{\star} \leq 1$, and is defined completely by the content of the component $i$ in the solution. Note that $X_{i}^{\star}$ is not necessarily the atomic fraction of $X_{i}$, but is related to it in such a way that $X_{i}^{\star}=X_{i}$ at the terminal compositions, i.e. at $X_{i}=0$ and 1.0. For example, in a solid solution of the type $(A, B, \ldots)_{m}(C, D, \ldots)_{n} P$, an appropriate expression of the activity of the component $A_{m} C_{n} P$ is $\left[\left(\chi_{\mathrm{A}}\right)^{m}\left(\chi_{\mathrm{C}}\right)^{n}\right] \gamma\left(\mathrm{A}_{m} C_{n} P\right)$, as discussed below, where $\chi$ stands for the site fraction of the specified species. In this case $X_{i}^{\bullet}$ (where $i \equiv A_{m} C_{n} P$ ) stands for the entire compositional term within the square bracket.

The state defined at $\left(P^{*}, T, X^{*}\right)$ is usually called the standard state. According to Equation 8 , the explicit expression or magnitude of $\gamma_{i}^{\star}$ depends on the choice of standard state of the component and the compositional function $X_{i}^{\star}$. This is because of the fact that $\mu_{i}(P, T, X)$ is an absolute quantity so that only two of the three parameters on the right hand side of Equation 8 may be chosen independently. It also follows from this equation that the activity of a component in its standard state is unity.

\section{Laws of dilute solutions}

In the dilute range, the activity of a solute $(i)$ that is actually present in a solution is found to obey Henry's law, which may be stated as follows.

$$
\mathrm{Lt}_{\mathrm{X} i \rightarrow 0}, a_{i}=K_{\mathrm{H}} X_{i},
$$

where $K_{\mathrm{H}}$ is a constant at a fixed $P-T$ condition. If $i$ represents a strong electrolyte (e.g. $\mathrm{HCl}$, which dissociates almost completely to $\mathrm{H}^{+}$and $\mathrm{Cl}^{-}$in aqueous solution), then $X_{i}$ in the above expression is replaced by $\left(X_{i}\right)^{n}$, where $n$ is the number of species to which the solute dissociates $\left(e . g\right.$. as $\left.X_{\mathrm{NaCl}} \rightarrow 0, a_{\mathrm{NaCl}} \propto\left(X_{\mathrm{NaCl}}\right)^{2}\right)$ (see Ganguly \& Saxena, 1987, for the proof). 
In the compositional range in which the activities of all solute components obey Equation 9, the solvent ( $j$ ) activity obeys Raoult's law, which may be stated as

$$
\mathrm{Lt}_{X j \rightarrow 1}, a_{j}=a_{j}^{0}(P, T) X_{j}
$$

where $a_{j}^{0}(P, T)$ is the activity of the pure component at the $P-T$ condition of interest. It is unity when the standard state of the component $i$ is chosen to be the state of pure component at the $P-T$ condition of interest.

Consider now a two-site (I and II) solid solution of the type ${ }^{\mathrm{I}}(A, B, \ldots)_{m}{ }^{\mathrm{II}}(C, D, \ldots)_{n} P$, e.g. garnet: $(\mathrm{Fe}, \mathrm{Mg}, \ldots)_{3}(\mathrm{Al}, \mathrm{Cr}, \ldots)_{2} \mathrm{Si}_{3} \mathrm{O}_{12}$. In this case, as $X_{j} \rightarrow 1$, the activity of the molecular component $A_{m} C_{n} P(\equiv j)$ will approach $\left[\left({ }^{1} \chi_{\mathrm{A}}\right)^{m}\left({ }^{\mathrm{II}} \chi_{\mathrm{C}}\right)^{n}\right]$, when pure $A_{m} C_{n} P$ at the $P-T$ condition of interest is chosen to be the standard state of the molecular component, i.e.

$$
\mathrm{Lt}_{X j \rightarrow 1}, a_{j}=\left[\left({ }^{1} \chi_{\mathrm{A}}\right)^{m}\left({ }^{\mathrm{II}} \chi_{\mathrm{C}}\right)^{n}\right] \equiv X_{j}^{*}
$$

Although Henry's law and Raoult's law were proposed independently, one follows from the other because of the Gibbs-Duhem relation (Eqn. 4b).

\section{Mixing and excess functions}

Using Equations 1 and 8, one obtains the following expression for the molar Gibbs energy, $G_{\mathrm{m}}$, of a solution.

$$
\begin{aligned}
G_{\mathrm{m}} & =\sum X_{i} \mu_{i}^{*}+R T \sum X_{i} \ln X_{i}^{*}+R T X_{i} \ln \gamma_{i}^{*} \\
& =\sum X_{i} \mu_{i}^{*}+\Delta G_{\mathrm{m}}^{\text {mix }} .
\end{aligned}
$$

The first term on the right represents a mechanical mixing term of the standard state chemical potentials, whereas $\Delta G_{\mathrm{m}}^{\mathrm{mix}}$ represents the deviation of the molar Gibbs energy of the solution from that of the mechanical mixture. Imposing the laws of dilute solutions (Eqns. 9 and 10) on the above relation, it can be shown (e.g. Ganguly \& Saxena, 1987) that the $G$ vs. $X$ curve must be convex downwards near the terminal regions $\left(d G / d X_{i} \rightarrow-\infty\right.$ as $\left.X_{i} \rightarrow 0\right)$.

A solution is said to be thermodynamically ideal when $\gamma_{i}^{*}=1$ for all components. Thus, the Gibbs energy of an ideal solution is always less than that of the mechanical mixture of the end-member components. The difference between the Gibbs energy of a real solution and that of an hypothetical ideal solution is known as the excess Gibbs energy of mixing of the solution, $\Delta G_{\mathrm{m}}^{\mathrm{xs}}$. Thus, we have

$$
\Delta G_{\mathrm{m}}^{\mathrm{xs}}=R T \sum X_{i} \ln \gamma_{i} \text {. }
$$

The other properties of a solution follow from Equation 12 through appropriate thermodynamic operations, viz., $H=(\partial G / T) / \partial(1 / T), S=-\partial G / \partial T$ and $V=\partial G / \partial P$ (note that since $G=H-T S$, it is not necessary to differentiate $G$ to derive both $H$ and $S$ ). Thus, one obtains the following expression for the molar entropy of mixing in an ideal solution

$$
\Delta S_{\mathrm{m}}^{\mathrm{mix}}(\text { ideal })=-R \sum X_{i} \ln X_{i}^{\star}
$$


By definition, the quantity $R T \ln \gamma_{i}$ represents the excess chemical potential (or excess partial Gibbs energy) of the component $i$. Consequently, from the definition of a partial property

$$
R T \ln \gamma_{i}=\left(\frac{\partial \Delta G^{\mathrm{xs}}}{\partial n_{i}}\right)_{P, T, n_{j} \neq n_{i}} .
$$

In terms of the molar property, we can obtain $R T \ln \gamma_{i}$ from Equation 5, or its multicomponent extension due to Darken (1950), and from Equation 6 on simply replacing $G_{\mathrm{m}}$ by $\Delta G_{\mathrm{m}}^{\mathrm{xs}}$. The latter operation is more convenient for a multicomponent solution.

\section{Reciprocal solutions}

Let us now consider a two-site (I and II) solid solution such as ${ }^{\mathrm{I}}(A, B)_{m}{ }_{m} \mathrm{II}(C, D)_{n} P$ in which there is no stoichiometric relation between the substitutions in the two sites, that is the ratio $A / B$ is independent of the ratio $C / D$. This type of solutions are known as reciprocal solutions. An example is the two-site garnet solid solution $(\mathrm{Fe}, \mathrm{Mg})_{3}(\mathrm{Al}, \mathrm{Cr})_{2} \mathrm{Si}_{3} \mathrm{O}_{12}$, where the inert part $\mathrm{Si}_{3} \mathrm{O}_{12}$ corresponds to $P$. The molar Gibbs energy of such a two-site binary reciprocal solution may be expressed using the reference surface illustrated in Figure 1 (Hillert \& Staffansson, 1970; Wood \& Nicholls, 1978; Hillert, 1998) according to

$$
\begin{aligned}
G_{\mathrm{m}} & =\left[\chi_{\mathrm{A}} \chi_{\mathrm{C}} G^{0}\left(A_{m} C_{n} P\right)+\chi_{\mathrm{B}} \chi_{\mathrm{C}} G^{0}\left(B_{m} C_{n} P\right)+\chi_{\mathrm{A}} \chi_{\mathrm{D}} G^{0}\left(A_{m} D_{n} P\right)\right. \\
& \left.+\chi_{\mathrm{B}} \chi_{\mathrm{D}} G^{0}\left(B_{m} D_{n} P\right)\right]+\left[m R T^{\mathrm{I}}\left(\sum \chi_{i} \ln \chi_{i}\right)+n R T^{\mathrm{II}}\left(\sum \chi_{i} \ln \chi_{i}\right)\right]+\Delta G_{\mathrm{m}}^{\mathrm{xs}},
\end{aligned}
$$

where the summation is carried out separately for each site indicated by a left hand superscript. The collection of terms within the second square brackets represents $-T S^{\mathrm{mix}}$ (ideal). This approach of representing $G_{\mathrm{m}}$ of a reciprocal solution with reference to the Gibbs energies of the end-member compounds, whether these compounds are real or hypothetical, has been called the compound energy model by Hillert and co-workers (e.g. Andersson et al., 1986; Hillert, 1998).

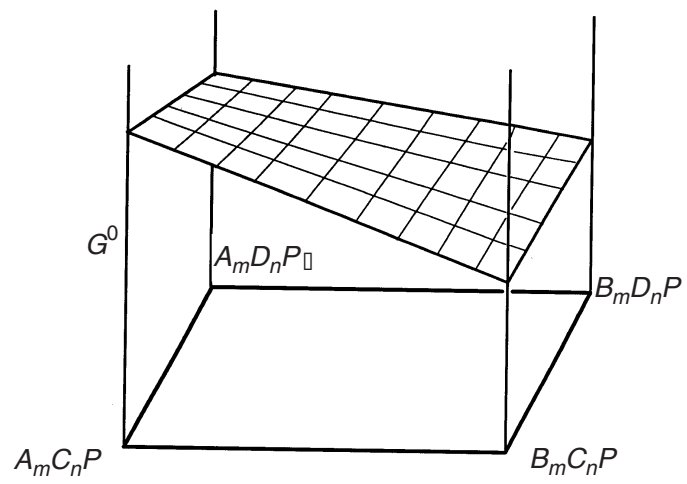

Fig. 1. Illustration of the Gibbs free $\left(G^{0}\right)$ surface defined by the mechanical mixtures of end-member components in a two-site binary reciprocal solid solution, $(A, B)_{m}(C, D)_{n} P$. The bounding binaries define the $G^{0}$ for the mechanical mixtures of end members in one-site solution. The ruled surface is non-planar. 
Assuming that the interactions within each site are ideal, in which case $\Delta G_{\mathrm{m}}^{\mathrm{xs}}$ in Equation 16 is zero, the chemical potential of an end-member component in a binary reciprocal solution is given by

$$
\mu\left(A_{m} C_{n} P\right)=\mu^{0}\left(A_{m} C_{n} P\right)+\Delta G^{0}(\mathrm{rec})\left(1-\chi_{\mathrm{A}}\right)\left(1-\chi_{\mathrm{C}}\right)+m R T \ln \left(\chi_{\mathrm{A}}\right)+n R T \ln \left(\chi_{\mathrm{C}}\right),
$$

where $\mu^{0}\left(A_{m} C_{n} P\right)$ is the Gibbs energy of the pure component $A_{m} C_{n} P$ at the $P-T$ condition of interest and $\Delta G^{0}(\mathrm{rec})$ is the Gibbs energy change of the homogeneous reciprocal reaction

$$
A_{m} C_{n}+B_{m} D_{n}=A_{m} D_{n}+B_{m} C_{n} .
$$

(It is obvious that in Equation 17, the standard state of a component is assumed to be the state of the pure component at the $P-T$ condition of interest.)

Equation 17 was first derived by Flood et al. (1954), and has subsequently been derived by others (e.g. Blander, 1964; Hillert \& Staffansson, 1970; Wood \& Nicholls, 1978; Hillert, 1998). This equation, and its extension to multisite-multicomponent solution, can be derived in a systematic way by using Equation 6, and carrying out the differentiations for the appropriate components within each sublattice (Wood \& Nicholls, 1978; Sundman \& Ågren, 1981; Hillert, 1998). Thus, for example, using Equation 6b, we have for the component $A_{m} C_{n} P$ in the two-site solution,

$$
\mu_{\mathrm{A}_{\mathrm{m}} \mathrm{C}_{\mathrm{n}} \mathrm{P}}=G_{\mathrm{m}}+\frac{\partial G_{\mathrm{m}}}{\partial X_{\mathrm{A}}}+\frac{\partial G_{\mathrm{m}}}{\partial X_{\mathrm{C}}}-\sum_{k} \frac{\partial G_{\mathrm{m}}}{\partial X_{k}},
$$

where the last summation is carried over both sublattices (the corresponding expression using Equation 6a should be obvious).

Equation 17 highlights an important property of a reciprocal solution, i.e. it behaves non-ideally (in the sense that the chemical potential of a component cannot be determined completely from a knowledge of the content of that component in the solution), even when the interactions within the individual sites are ideal. Comparing Equations 8 and 17, we then write the following expression of the activity coefficient of the component $A_{m} C_{n} P$, when the intrasite interactions are ideal:

$$
R T \ln \gamma\left(A_{m} C_{n} P\right)_{\mathrm{rec}}=\Delta G^{0}(\mathrm{rec})\left(1-\chi_{\mathrm{A}}\right)\left(1-\chi_{\mathrm{C}}\right),
$$

where the subscript rec is used to highlight that this is a component of the overall activity coefficient that is simply due to the reciprocal nature of the solution. The above equation may be written in a general form as

$$
R T \ln \gamma\left(i_{m} j_{n} P\right)_{\mathrm{rec}}= \pm\left(1-\chi_{i}\right)\left(1-\chi_{j}\right) \Delta G^{0}(\mathrm{rec}),
$$

where the positive sign holds when $i_{m} j_{n} P$ is a reactant component, and the negative sign holds when it is a product component of the reciprocal reaction. Multicomponent extension of the above expression can be found in Wood \& Nicholls (1978) and Hillert (1998), or derived from Equation 19 following the procedure outlined above. 
Comparing the statistical-mechanical and thermodynamic derivations of the activity of a component in a reciprocal solution, Førland (1964) suggested that the entropy change of a reciprocal reaction should be very small, which implies that the $\Delta G^{0}$ of a reciprocal reaction should be quite insensitive to temperature change. This fact was utilised by Liermann \& Ganguly (1999) to model the (reciprocal) effect of the variation of $\mathrm{Al} / \mathrm{Cr}$ ratio in spinel on the $(\mathrm{Fe}, \mathrm{Mg})$ fractionation between orthopyroxene, $(\mathrm{Fe}, \mathrm{Mg}) \mathrm{SiO}_{3}$, and spinel $(\mathrm{Fe}, \mathrm{Mg})(\mathrm{Al}, \mathrm{Cr})_{2} \mathrm{O}_{4}$. Natural data on the $\mathrm{Fe}-\mathrm{Mg}$ distribution coefficient, $K_{\mathrm{D}}(\mathrm{Fe}-\mathrm{Mg})$, between olivine, $(\mathrm{Fe}, \mathrm{Mg})_{2} \mathrm{SiO}_{4}$, and spinel show a systematic variation with $\mathrm{Cr} /(\mathrm{Cr}+\mathrm{Al})$ content of spinel in an isothermal suite of metamorphic rocks (Evans \& Frost, 1975). These data show a linear relation between $\ln K_{\mathrm{D}} v s . \chi_{\mathrm{Cr}}$ (spinel) that can be derived by expressing the activity coefficients of $\mathrm{FeAl}_{2} \mathrm{O}_{4}$ and $\mathrm{MgAl}_{2} \mathrm{O}_{4}$ components in spinel according to Equation 21, and assuming ideal mixing between $\mathrm{Fe}$ and $\mathrm{Mg}$ in both spinel and olivine (Ganguly \& Saxena, 1987), viz., $R T \ln K_{\mathrm{D}}=R T \ln K+\Delta G^{0}(\mathrm{rec}) X_{\mathrm{Cr}}(\mathrm{Spl})$ where $K_{\mathrm{D}}=$ $\left(\mathrm{Mg} / \mathrm{Fe}^{2+}\right)^{\mathrm{Ol}} /\left(\mathrm{Mg} / \mathrm{Fe}^{2+}\right)^{\mathrm{Spl}}$, where $K$ is the equilibrium constant of the exchange reaction $\mathrm{Fe}^{2+}-\mathrm{Ol}+\mathrm{Mg}-\mathrm{Spl} \leftrightarrow \mathrm{Mg}-\mathrm{Ol}+\mathrm{Fe}^{2+}-\mathrm{Spl}$.

When the sites behave non-ideally, the overall activity coefficient of a component has to be expressed by a combination of Equation 21 and additional terms reflecting the non-ideal interactions within the individual sites including their mutual interdependence. The reason for the cross interactions between the sites in a solid solution may be appreciated by noting that the bond distance within site I may be affected by a change of composition in site II, and vice versa.

\section{Ionic solution model}

The classical and statistical thermodynamic basis of the so-called ionic solution model, which has been used extensively in the treatment of mineral solid solutions, was discussed in detail by Ganguly \& Saxena (1987). Thus, only a brief exposition of the model is given in this section. It should be noted at the outset that all expressions for the activity of a component are equivalent as long as these are based on the same standard state of the component. The explicit expression of the activity coefficient of a component in a solution, therefore, depends on the form of the activity expression. The ionic solution model provides a rational approach towards the development of such expressions.

\section{Single-site solutions}

The ionic solution model for a solid solution involving substitution in a single type of site may be illustrated by considering a solution such as olivine, $(\mathrm{Fe}, \mathrm{Mg})_{2} \mathrm{SiO}_{4}$. According to this model, the activity of an end-member component, $A_{m} F\left(\right.$ e.g. $\left.\mathrm{Mg}_{2} \mathrm{SiO}_{4}\right)$ is given by

$$
a\left(A_{m} F\right)=\left(\chi_{\mathrm{A}} \gamma_{\mathrm{A}}\right)^{m},
$$

where $\chi_{\mathrm{A}}$ is the atomic fraction of $A$ within its specific site, and $\gamma_{\mathrm{A}}$ is the activity coefficient of the ion $A$ reflecting non-ideal interactions with other ions within the same site. $\gamma_{\mathrm{A}}$ may be viewed as the activity coefficient of the normalised component $A F_{1 / m}$ (e.g. $\mathrm{MgSi}_{0.5} \mathrm{O}_{2}$ ). Note that $\chi_{\mathrm{A}}$ equals the mole fraction of the molecular component $A_{m} F$ 
(e.g. $\chi_{\mathrm{Mg}}=X\left(\mathrm{Mg}_{2} \mathrm{SiO}_{4}\right)$ in olivine). A simple justification of this relation lies in the expression for the configurational entropy of mixing, which can be derived from the Boltzmann relation (e.g. Ganguly \& Saxena, 1987), assuming the simplest possible model for the distribution of atoms, namely that these are distributed randomly in the solid solution within their structural sites. For a solution of the type $(A, B, \ldots)_{m} P$, this relation is

$$
\begin{aligned}
\Delta S_{\mathrm{m}}(\mathrm{conf}) & =-m R \sum \chi_{i} \ln \chi_{i} \\
& =-R \sum \chi_{i} \ln \left(\chi_{i}\right)^{m} .
\end{aligned}
$$

Comparing the above equation with the simplest thermodynamic expression for the entropy of mixing, namely that of an ideal solution as given by Equation 14, we obtain

$$
X_{i}^{*}=\left(\chi_{i}\right)^{m} .
$$

Thus, in general,

$$
a\left(A_{m} P\right)=\left(X_{\mathrm{A}}^{*} \gamma_{\mathrm{A}}^{*}\right)=\left(\chi_{\mathrm{A}} \gamma_{\mathrm{A}}\right)^{m},
$$

which yields the ideal behaviour, $a\left(A_{m} P\right)=\left(\chi_{\mathrm{A}}\right)^{m}$, as $X\left(A_{m} P\right) \rightarrow 1$.

\section{Reciprocal and disordered solutions}

Comparing Equation 17 with the expression of $\mu\left(A_{m} C_{n} P\right)$, written in terms of the activity of the component $A_{m} C_{n} P$, i.e.

$$
\mu\left(A_{m} C_{n} P\right)=\mu^{0}\left(A_{m} C_{n} P\right)+R T \ln a\left(A_{m} C_{n} P\right),
$$

we obtain for a reciprocal solution with ideal intrasite interactions

$$
a\left(A_{m} C_{n} P\right)=\left[\left(\chi_{\mathrm{A}}\right)^{m}\left(\chi_{\mathrm{C}}\right)^{n}\right] \gamma\left(A_{m} C_{n} P\right),
$$

where $\gamma\left(A_{m} C_{n} P\right)$ is given by Equation 21. If, however, the intrasite interactions were non-ideal, but the sites behave independently of one another, then we could write (Wood \& Nicholls, 1978)

$$
\gamma\left(A_{m} C_{n} P\right)=\left[\left({ }^{\mathrm{I}} \gamma_{\mathrm{A}}\right)^{m}\left({ }^{\mathrm{II}} \gamma_{\mathrm{C}}\right)^{n}\right] \exp \left[ \pm\left(1-\chi_{\mathrm{A}}\right)\left(1-\chi_{\mathrm{C}}\right)\left(\Delta G^{0}(\mathrm{rec}) / R T\right)\right],
$$

where the sign convention is the same as in Equation 21. The interdependence between the mixing properties in the two sites would require additional terms, or may be absorbed in some cases within the site activity coefficient terms.

As discussed by Ganguly (1982) and Ganguly \& Saxena (1987), the above equations are also applicable to solid solutions of the type ${ }^{\mathrm{I}}(A, B)_{m}{ }^{\mathrm{II}}(A, B)_{n} P$ in which the species $A$ and $B$ disorder or fractionate between the structural sites I and II. An example of this type of solution is orthopyroxene, ${ }^{\mathrm{M} 1}(\mathrm{Fe}, \mathrm{Mg})^{\mathrm{M} 2}(\mathrm{Fe}, \mathrm{Mg}) \mathrm{Si}_{2} \mathrm{O}_{6}$, in which $\mathrm{Fe}$ and $\mathrm{Mg}$ disorder between the two non-equivalent octahedral sites, M1 and M2 (Ghose, 1982). (The state of the Fe-Mg disordering in orthopyroxene is an important indicator of the cooling rates of the host rocks, e.g. Ganguly et al., 1982.) In the absence of adequate data on the thermodynamic mixing properties, it has been a common practice, however, to express the activity of an end-member component in such a disordered twosite solid solution in terms of what has been known as two-site ideal model, i.e.

$$
\left.a\left(A_{m} A_{n} P\right)=\left({ }^{\mathrm{I}} \chi_{\mathrm{A}}\right)^{m}\right]\left({ }^{\mathrm{II}} \chi_{\mathrm{A}}\right)^{n} .
$$


By comparing with Equations 27 and 28, it should be noted that this expression not only implies that ${ }^{\mathrm{I}} \gamma_{\mathrm{A}}={ }^{\mathrm{II}} \gamma_{\mathrm{B}}=1$, but also that $\Delta G^{0}(\mathrm{rec}) / R T=0$. In addition, because of stoichiometric relation between the atomic fraction of $A$ in the bulk crystal, $X_{\mathrm{A}}$, and within the two sites, i.e. $X_{\mathrm{A}}=p\left({ }^{\mathrm{I}} \chi_{\mathrm{A}}\right)+q\left({ }^{\mathrm{II}} \chi_{\mathrm{A}}\right)$, where $p=m /(m+n)$ and $q=(1-p)$, the right hand term of Equation 29 is $\leq X_{\mathrm{A}}$, the equality holding only in the case of complete disorder, i.e. when ${ }^{\mathrm{I}} \chi_{\mathrm{A}}={ }^{\mathrm{II}} \chi_{\mathrm{A}}$. Thus, an activity expression in terms of two-site ideal model implies a negative deviation from ideality for the mixing of the macroscopic components, i.e. $a\left(A_{m} A_{n} P\right)<X_{\mathrm{A}}$. For example, the often used expression $a\left(\mathrm{MgSiO}_{3}\right)=$ $\left({ }^{\mathrm{M} 1} \chi_{\mathrm{Mg}}\right)^{1 / 2}\left({ }^{\mathrm{M} 2} \chi_{\mathrm{Mg}}\right)^{1 / 2}$ for orthopyroxene solid solution, ${ }^{\mathrm{M} 1}(\mathrm{Fe}, \mathrm{Mg}, \ldots)_{0.5}{ }^{\mathrm{M} 2}(\mathrm{Fe}, \mathrm{Mg}, \ldots)_{0.5}$, implies that $a\left(\mathrm{MgSiO}_{3}\right)<X_{\mathrm{Mg}}$, which is not compatible with the available calorimetric and phase equilibrium data (Stimpfl et al., 1999).

\section{Coupled substitutions}

There are many solid solutions that require coupled substitutions of ions in order that the macroscopic electrical neutrality can be preserved. An example is plagioclase feldspar, which has the end-member components $\mathrm{NaAlSi}_{3} \mathrm{O}_{8}$ and $\mathrm{CaAl}_{2} \mathrm{Si}_{2} \mathrm{O}_{8}$, involving the coupled substitution $\left(\mathrm{Na}^{+} \mathrm{Si}^{4+}\right) \leftrightarrow\left(\mathrm{Ca}^{2+} \mathrm{Al}^{3+}\right)$. When local electroneutrality is maintained in the solution, a replacement of $\mathrm{Na}^{+}$by $\mathrm{Ca}^{2+}$ is accompanied by a replacement of the nearest neighbour $\mathrm{Si}^{4+}$ by $\mathrm{Al}^{3+}$ in the tetrahedral site. In this case, the expression for the activity of an end-member component (e.g. $\left.\mathrm{NaAlSi}_{3} \mathrm{O}_{8}\right)$ in terms of the ionic solution model should consider $X$ in Equation 22 as the mole fraction of the coupled species $\left(e . g . X_{\mathrm{NaSi}}\right)$, and equate the exponent $\mathrm{m}$ to the number of moles such species per mole of the solid solution. Thus, recasting the formula for plagioclase solid solution as $(\mathrm{NaSi}, \mathrm{CaAl})\left(\mathrm{AlSi}_{2} \mathrm{O}_{8}\right)$, we have

$$
a(\mathrm{Ab})=X_{\mathrm{NaSi}} \gamma_{\mathrm{NaSi}} \equiv X_{\mathrm{Ab}} \gamma_{\mathrm{Ab}} \text {. }
$$

The interested reader is referred to Ganguly \& Saxena (1987) for further discussion on this problem, especially when the substitution of $\mathrm{Na}$ for $\mathrm{Ca}^{2+}$ is partly or completely decoupled from the substitution in the tetrahedral site at relatively high temperature.

\section{One-site binary mixing models}

The mixing models described in this section apply to solid solutions in which the substitutions are restricted to one site or in which the substitutions in different sites are coupled so that a site atomic fraction equals a molecular fraction, such as in the case of the plagioclase solid solution. When the solid solution involves independent multiple site substitutions, such as in garnet, the mixing properties within each site may also be treated in terms of the models described in this section. The different solution models deal with the different types of representation of the excess thermodynamic quantities as functions of composition. The fundamental expression is that of $\Delta G_{\mathrm{m}}^{\mathrm{xs}}$ as a function of composition, from which all other excess thermodynamic properties may be derived through standard thermodynamic operations, as discussed above (e.g. Eqns. 14 and 15). I will first deal with binary solutions and then ternary and higher order solutions. 


\section{Guggenheim or Redlich-Kister, Simple Mixture and Regular Solution models}

Guggenheim (1937) suggested that the molar excess Gibbs energy of mixing of a binary solution may be represented by the polynomial expression,

$$
\Delta G_{\mathrm{m}}^{\mathrm{xs}}=X_{1} X_{2}\left[A_{0}+A_{1}\left(X_{1}-X_{2}\right)+A_{2}\left(X_{1}-X_{2}\right)^{2}+\ldots .\right],
$$

where the $A$ 's are constants at a fixed $P-T$ condition. This polynomial satisfies the requirement that $G_{\mathrm{m}}^{\mathrm{xs}}$ must vanish at the terminal compositions (i.e. $X_{1}=X_{2}=0$ ). Operating on this relation according to Equation 5, and noting that $R T \ln \gamma_{i}=\Delta G_{i}^{\mathrm{xs}}$, we have

$$
R T \ln \gamma_{1}=X_{2}^{2}\left[A_{0}+A_{1}\left(3 X_{1}-X_{2}\right)+A_{2}\left(X_{1}-X_{2}\right)\left(5 X_{1}-X_{2}\right)+\ldots\right]
$$

and

$$
R T \ln \gamma_{2}=X_{1}^{2}\left[A_{0}-A_{1}\left(3 X_{2}-X_{1}\right)+A_{2}\left(X_{2}-X_{1}\right)\left(5 X_{2}-X_{1}\right)+\ldots\right] .
$$

These expressions for the activity coefficients were first derived by Redlich \& Kister (1948) and are usually referred to as Redlich-Kister relations. Somehow, even the Guggenheim polynomial is often referred to as the Redlich-Kister expression of excess Gibbs energy, which does not seem justified (this is possibly due to the fact that these authors recommended an extension of the Guggenheim polynomial to the ternary system, as discussed below).

When the $A$ constants with odd subscripts, $A_{1}, A_{3}$ etc. are zero, the $\Delta G_{\mathrm{m}}^{\mathrm{xs}}$ becomes symmetric with respect to composition, and are, thus, called symmetric solutions by Guggenheim (1967). The simplest functional form of a nonideal solution is the one in which all but the first constant in Equation 31 is zero. In this case, $\Delta G_{\mathrm{m}}^{\mathrm{xs}}$ has a parabolic symmetry with respect to composition. Guggenheim (1967) called this type of solution a Simple Mixture, as it represents the simplest form of deviation from ideality. Conventionally, $A_{0}$ is replaced by the symbol $W$ or $W^{\mathrm{G}}$ when the solution behaves as a Simple Mixture so that, according to the last two equations

$$
\Delta G_{\mathrm{m}}^{\mathrm{xs}}=W^{\mathrm{G}} X_{1} X_{2}
$$

and

$$
R T \ln \gamma_{i}=W^{\mathrm{G}}\left(1-X_{i}\right)^{2},
$$

where $i$ is either component 1 or 2 (see Eqn. 51 for the microscopic interpretation of $W$ )

The dependence of $W^{\mathrm{G}}$ on $P$ and $T$ are given, respectively, by

$$
\begin{aligned}
& \left(\frac{\partial W^{\mathrm{G}}}{\partial P}\right)_{T}=\frac{1}{X_{1} X_{2}}\left(\frac{\partial \Delta G^{\mathrm{xs}}}{\partial P}\right)_{T}=\frac{\Delta V^{\mathrm{xs}}}{X_{1} X_{2}}, \\
& \left(\frac{\partial W^{\mathrm{G}}}{\partial T}\right)_{P}=\frac{1}{X_{1} X_{2}}\left(\frac{\partial \Delta G^{\mathrm{xs}}}{\partial T}\right)_{P}=-\frac{\Delta S^{\mathrm{xs}}}{X_{1} X_{2}} .
\end{aligned}
$$

Hildebrand (1929) introduced the term Regular Solution for the type of solutions which obey Equation 33, but in which the interaction parameter $W^{\mathrm{G}}$ is independent of $P$ 
and $T$. Thus, a regular solution is a special class of a simple mixture with ideal volume and entropy of mixing. However, this distinction is not strictly followed in modern usage in that any solution which obeys the functional form of Equation 33 is often referred to as regular solution. I will also use the term regular solution in the sense of simple mixture. Following Thompson (1967), $W^{\mathrm{G}}$ is commonly decomposed into enthalpic $\left(W^{\mathrm{H}}\right)$, entropic $\left(W^{\mathrm{S}}\right)$ and volumetric $\left(W^{\mathrm{V}}\right)$ terms. It can be shown that

$$
W^{\mathrm{G}}(P, T)=W^{\mathrm{H}}(1 \mathrm{bar}, T)-T W^{\mathrm{S}}(1 \mathrm{bar}, T)+\int_{1}^{P} W^{\mathrm{V}} d P
$$

Assuming $W^{V}$ to be independent of $P$, the last term is often written as a $P W^{\mathrm{V}}$ term in geological literature, since, usually $P>1$ bar under geological conditions. The temperature dependence of $W^{\mathrm{H}}$ and $W^{\mathrm{S}}$ is related to the excess heat capacity of mixing, which is due to non-linear change of vibrational properties as a function of composition. Due to an extreme paucity of heat capacity data for solid solutions, the $W^{\mathrm{H}}$ and $W^{\mathrm{S}}$ terms are almost invariably assumed to be constants. However, as shown by Vinograd (2001) from analysis of spectroscopic data in Prp-Grs and Di-CaTs solid solutions, there could be significant temperature dependence of these parameters.

When the thermodynamic mixing properties of solid solutions appear symmetrical with respect to composition, or show moderate deviation from symmetric behaviour, these are usually fitted by regular or subregular (see below) solution models. However, the data are rarely good and sufficient enough to permit discrimination if the symmetry is truly parabolic in nature. Recently, Stimpfl et al. (1999) carried out a detailed study, by single crystal X-ray diffraction, of the distribution of $\mathrm{Fe}^{2+}$ and $\mathrm{Mg}$ between the non-equivalent octahedral sublattices, $M 1$ and $M 2$, in essentially binary orthopyroxene solid solution, ( $\mathrm{Fe}, \mathrm{Mg}) \mathrm{SiO}_{3}$, as a function of temperature. From these data, they calculated the $\Delta S^{\text {mix }}$ of Fe and $\mathrm{Mg}$, assuming that the distribution is random within each sublattice. Their results show that the $\Delta S^{\text {mix }}$ is essentially symmetric with respect to composition, but the relation is not parabolic. Instead, the best fit to the data requires two even parameters, $A_{0}^{\mathrm{s}}$ and $A_{2}^{\mathrm{s}}$, in Guggenheim's polynomial expression, where the superscript $\mathrm{s}$ denotes terms related to the expression of $\Delta S_{\mathrm{m}}^{\mathrm{xs}}$, when expressed according to the form of Equation 31.

\section{Subregular model}

This is the simplest model for asymmetric solutions, and has been used most extensively in the petrological and mineralogical literature. It represents a simple extension of the regular solution model by making the parameter $W^{\mathrm{G}}$ in Equation 33 a simple function of composition as

$$
W^{\mathrm{G}}(\mathrm{SR})=W_{21}^{\mathrm{G}} X_{1}+W_{12}^{\mathrm{G}} X_{2}
$$

so that

$$
\Delta G^{\mathrm{xs}}(\mathrm{SR})=\left(W_{21}^{\mathrm{G}} X_{1}+W_{12}^{\mathrm{G}} X_{2}\right) X_{1} X_{2},
$$

where SR implies subregular, and $W_{i j}^{\mathrm{G}}$ is a function only of $P$ and $T$. It is obvious that near the terminal regions $X_{1}=1$ and $X_{2}=1, W^{\mathrm{G}}(\mathrm{SR})$ is approximated by $W_{21}^{\mathrm{G}}$ and $W_{12}^{\mathrm{G}}$, 
respectively. Thus, the subregular model is simply a weighted average of two regular solution models fitted to the data near the two terminal segments of a binary solution. Each subregular $W_{i j}^{\mathrm{G}}$ may also be decomposed according to Equation 37.

The subregular formulation follows from Guggenheim's polynomial expression for $\Delta G_{\mathrm{m}}^{\mathrm{xs}}$, Equation 31, by truncating it after the second term and using the identity $A_{0}=A_{0}\left(X_{1}+X_{2}\right)$, which yields

$$
\Delta G_{\mathrm{m}}^{\mathrm{xs}}(\mathrm{SR})=\left[\left(A_{0}+A_{1}\right) X_{1}+\left(A_{0}-A_{1}\right) X_{2}\right] X_{1} X_{2} .
$$

On substitution of $W_{12}^{\mathrm{G}}$ and $W_{21}^{\mathrm{G}}$ for the collection of constants within the first and second set of parentheses, respectively, Equation 40 reduces to the standard subregular form.

\section{Darken's quadratic formulation}

Darken (1967) pointed out that when the activity coefficient of a solvent component (say component 1) obeys the regular solution relation, as given by Equation 34, then the Gibbs-Duhem relation (Eqn. 4b) only requires that the activity coefficient of the solute component must obey the relation

$$
R T \ln \gamma_{2}=W^{\mathrm{G}}\left(1-X_{2}\right)^{2}+I,
$$

where $I$ is an integration constant. In order that the component 2 conforms to Raoultian behaviour (Eqn. 10) as $X_{2} \rightarrow 1$, the integration constant must be zero when $\gamma_{1}$ obeys the regular behaviour over the entire range of composition. If $\gamma_{1}$ conforms to the regular solution property over a restricted compositional range only near the terminal region 1 , then $\gamma_{2}$ will conform to Equation 41 over the same compositional range with $I \neq 0$. Thus, according to Equation 13, $\Delta G_{\mathrm{m}}^{\mathrm{xs}}$ near the terminal region 1 is given by,

$$
\Delta G_{\mathrm{m}}^{\mathrm{xs}}=W^{\mathrm{G}} X_{1} X_{2}+I X_{2} .
$$

This is known as Darken's Quadratic Formulation (DQF).

Using Equation 12 and rearranging terms, the molar Gibbs energy of a solution obeying $D Q F$ in the terminal region 1, where the solvent component 1 obeys regular solution behaviour, is given by

$$
\begin{aligned}
G_{\mathrm{m}} & =X_{1} G_{1}^{0}+X_{2}\left(G_{2}^{0}+I\right)+\Delta G_{\mathrm{m}}^{\mathrm{mix}} \\
& =X_{1} G_{1}^{0}+X_{2} G_{2}{ }^{\prime}+\Delta G_{\mathrm{m}}^{\mathrm{mix}},
\end{aligned}
$$

where $\Delta G_{\mathrm{m}}^{\mathrm{mix}}$ has the same expression as a regular solution, viz.,

$$
\Delta G_{\mathrm{m}}^{\mathrm{mix}}=\Delta G_{\mathrm{m}}^{\mathrm{mix}}(\text { ideal })+W^{\mathrm{G}} X_{1} X_{2}
$$

Thus, as noted by Powell (1987), a solution obeying DQF in the terminal region 1 may be viewed as a regular solution between the real end member 1 and a hypothetical end member whose molar Gibbs energy, $G_{2}^{\prime}$, is given by that of the end member 2 plus the value of the integration constant, I.

By analysing the experimentally determined activity coefficient data on a number of liquid binary alloys, especially those in which Fe was the solvent, Darken (1967) showed that while the solvent 1 followed regular solution behaviour up to a certain level of addition of the solute component 2 , the latter followed the relation described by 
Equation 41, with $I \neq 0$, over the same range of concentration. From these observations, Darken (1967) suggested that it may be possible to treat many solutions in terms of the Quadratic Formulation in the two terminal regions, each with characteristic values of $W$ and $I$. The behaviour of the intermediate compositional region would be more complex since it has to make the transition from the quadratic properties of one terminal region to those of the other.

For those solutions which conform to DQF in the two terminal regions, the intermediate region could follow a relation that is a weighted average of those of the terminal regions in much the same way as the expression of $\Delta G_{\mathrm{m}}^{\mathrm{xs}}$ of a subregular solution represents a weighted average of the regular solution expressions in the terminal regions (Eqn. 39). In that case, $\Delta G_{\mathrm{m}}^{\mathrm{xs}}$ of the intermediate segment of the solution conforming to DQF in the terminal regions (Eqn. 42) is given by

$$
\begin{aligned}
\Delta G_{\mathrm{m}}^{\mathrm{xs}}(1-2) & =X_{1}\left[W_{21}^{\mathrm{G}} X_{1} X_{2}+I_{21} X_{2}\right]+X_{2}\left[W_{12}^{\mathrm{G}} X_{1} X_{2}+I_{12} X_{1}\right] \\
& =X_{1} X_{2}\left[W_{21}^{\mathrm{G}} X_{1}+W_{12}^{\mathrm{G}} X_{2}+I_{21}+I_{12}\right],
\end{aligned}
$$

where the subscript $i j$ represents the property of the terminal region $j$. Note that when $X_{i} \rightarrow 1$, the $\Delta G_{\mathrm{m}}^{\mathrm{xs}}$ is given by only the $X_{i}[\ldots]$ term after the first equality in the above expression.

Powell (1987) analysed the available molar volume data of several binary mineral solid solutions, and showed that the data in the two terminal segments are better described by DQF than by regular solution model. His analysis is presented below. Using Equation 45 and the identity $I=G_{2}{ }^{\prime}-G_{2}^{0}$ (Eqn. 43), we obtain the following expression for $\Delta V^{\text {mix }}$ for the terminal region 1 , if the solution obeys DQF in that region.

$$
\begin{aligned}
\Delta V_{\mathrm{m}}^{\mathrm{mix}} & \equiv \Delta V_{\mathrm{m}}^{\mathrm{xs}}=\frac{\partial \Delta G_{\mathrm{m}}^{\mathrm{xs}}}{\partial P}=X_{1} X_{2} \frac{\partial W_{21}^{\mathrm{G}}}{\partial P}+X_{2} \frac{\partial I_{21}}{\partial P} \\
& =X_{1} X_{2} W_{21}^{\mathrm{V}}+X_{2}\left(V_{2}^{\prime}-V_{2}^{0}\right)
\end{aligned}
$$

or

$$
\frac{\Delta V_{\mathrm{m}}^{\mathrm{mix}}}{X_{2}}=X_{1} W_{21}^{\mathrm{V}}+\left(V_{2}^{\prime}-V_{2}\right) .
$$

Similarly for the terminal region 2 , we have

$$
\frac{\Delta V_{\mathrm{m}}^{\mathrm{mix}}}{X_{1}}=\left(X_{2}\right) W_{12}^{\mathrm{V}}+\left(V_{1}^{\prime}-V_{1}^{0}\right) .
$$

On the other hand, if a solution obeys the subregular behaviour over the entire compositional range, then using Equation 39, and following the same procedure, we have

$$
\frac{\Delta V_{\mathrm{m}}^{\mathrm{mix}}}{X_{1}\left(1-X_{1}\right)}=W_{21}^{\mathrm{V}} X_{1}+W_{12}^{\mathrm{V}} X_{2}=W_{12}^{\mathrm{V}}+X_{1}\left(W_{21}^{\mathrm{V}}-W_{12}^{\mathrm{V}}\right) \text {. }
$$


Thus, if a solution obeys the subregular behaviour, then the function on the left-hand side of the above expression should change linearly with composition. Figure 2 a shows the data for the microcline $\left(\mathrm{KAlSi}_{3} \mathrm{O}_{8}\right)$ and low-albite $\left(\mathrm{NaAlSi}_{3} \mathrm{O}_{8}\right)$ solid solution (Kroll et al., 1986) plotted in the manner suggested by Equation 49. It is evident that the data do not describe the linear relation expected from the subregular model. Figures $2 \mathrm{~b}$ and $2 \mathrm{c}$ show the same volumetric data plotted according to the forms of $D Q F$ in the terminal regions 2 (Eqn. 48) and 1 (Eqn. 47), respectively. The expected linear relations (solid lines) are followed in the terminal regions. [However, Powell (1987) seems to have overextended the linear relation in the terminal region 1 (Fig. 1c). A more appropriate linear fit to the data in this region should have been one with a smaller slope and better satisfying the data near $X=1]$.
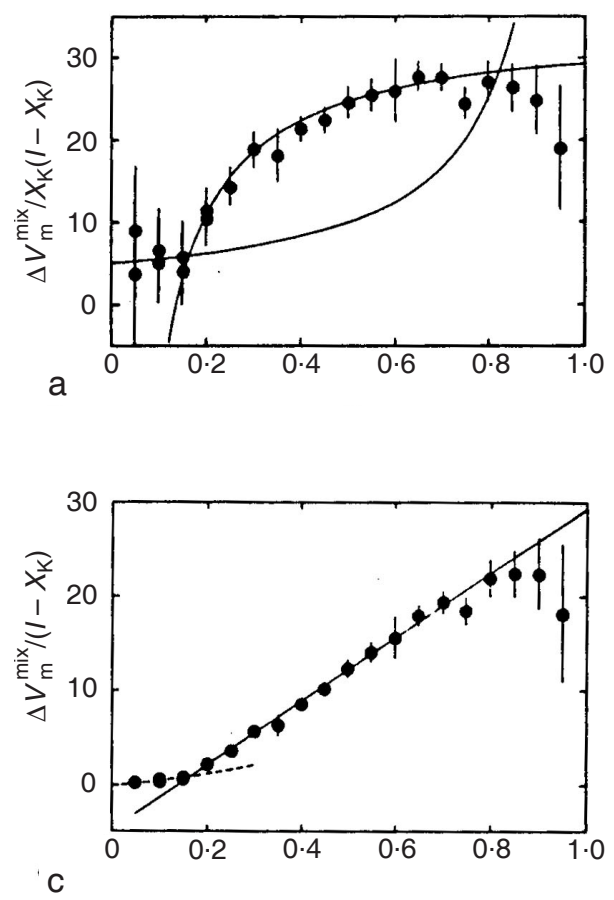

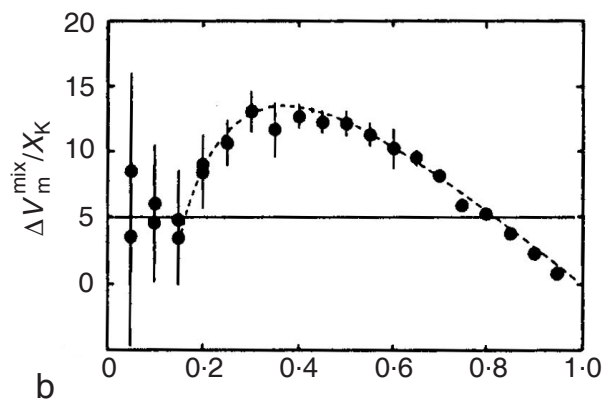

प

Fig. 2. Volume-composition relation of microcline $\left(\mathrm{KAlSi}_{3} \mathrm{O}_{8}\right)$-low albite $\left(\mathrm{NaAlSi}_{3} \mathrm{O}_{8}\right)$ solid solution displayed according to (a) subregular model (Eqn. 49) and $(\boldsymbol{b}-\boldsymbol{c})$ Darken's quadratic formulation $(D Q F)$. $V$ represents unit cell volume in $\AA^{3}$. In Figs. (b-c), the data are displayed according to the $D Q F$ equations for the terminal regions 2 and 1 , respectively (see text). The figure is reproduced from Powell (1987).

In applying DQF to treat the mixing property data, one needs to be careful about the quality of the data. Since the data are divided into three segments, two terminal regions and one central region, there is greater flexibility in fitting the data, which permits better conformity of relatively poor quality data to DQF than to the subregular model. This point can be illustrated by considering the volumetric data along the pyrope-grossular join. Powell (1987) showed that the available data are much better described by DQF than by the subregular model. Since then, precise volumetric data were obtained on this join by Ganguly et al. (1993) and Bosenick \& Geiger (1997). As illustrated in Figure 3, neglecting two anomalous measurements, these data conform well to the subregular model. 


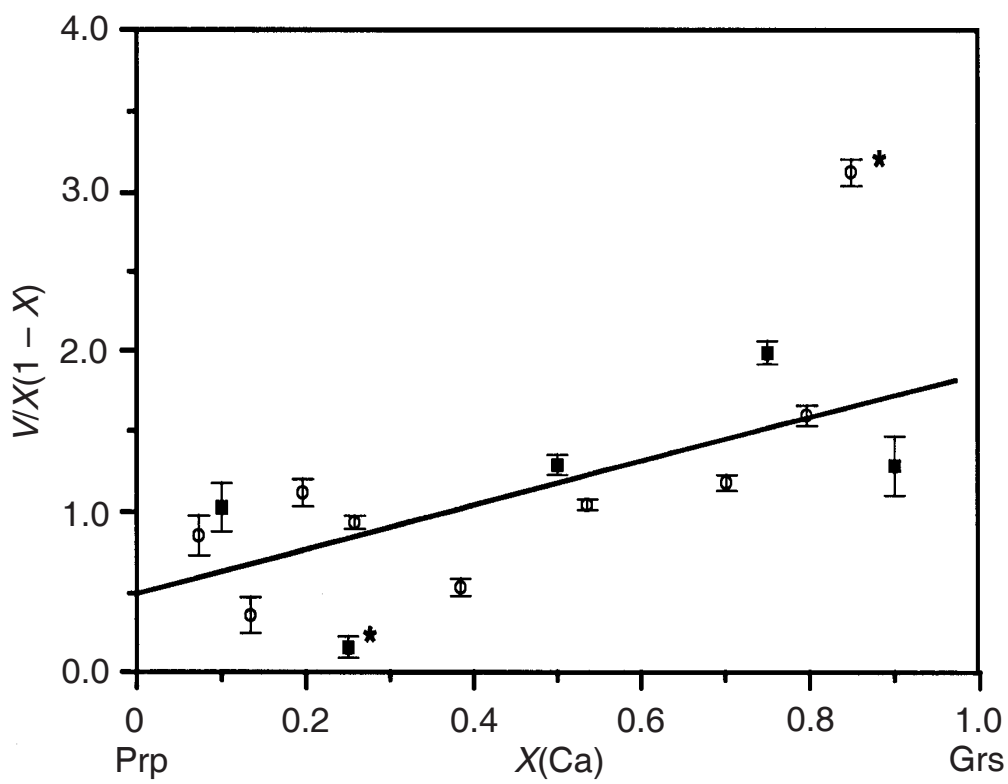

Fig. 3. Volume-composition relation of the pyrope $\left(\mathrm{Mg}_{3} \mathrm{Al}_{2} \mathrm{Si}_{3} \mathrm{O}_{12}\right)$-grossular $\left(\mathrm{Ca}_{3} \mathrm{Al}_{2} \mathrm{Si}_{3} \mathrm{O}_{12}\right)$ solid solution displayed according to the linear form suggested by subregular behaviour. $V$ is the molar volume in $\mathrm{cm}^{3}$. The data are from Ganguly et al. (1993; circles) and Bosenick \& Geiger (1997; filled squares). The vertical bars represent $\pm 1 \sigma$ centred on the symbols. The fitted line neglects the anomalous data marked by asterisks.

\section{Quasi-chemical and related models}

In the simple mixture model, the distribution of species in a solution has been considered to be random, even though the pair-potential energies are different, thus leading to nonzero enthalpy of mixing. However, this cannot be strictly correct since a species would tend to be preferentially surrounded by the ones with which it has a relatively stronger potential energy of interaction. The atomic distribution would be effectively random at high temperature when the thermal energy per mole, $R T$, is sufficiently high to prevent clustering of such species. Guggenheim (1952) sought to remedy this logical problem with the simple mixture model by considering that in a binary solution, the distribution of the $1-1,2-2$ and $1-2$ pairs is related to the energy change of the homogeneous chemical reaction

$$
1-1+2-2=2(1-2) \text {. }
$$

The resultant thermodynamic mixing model is known as the quasi-chemical (QC) model because of its appeal to a chemical reaction among the different pairs in the solution, and representation of the equilibrium concentration of these pairs in much the same way as the equilibrium concentration of components is expressed by an equilibrium constant of a chemical reaction. 
From consideration of the total potential energy of a lattice consisting of 1-1, 2-2 and 1-2 pairs, and neglecting the effect of long range forces, Guggenheim (1952) introduced an interchange energy, $W$, according to

$$
W=L Z\left[\Gamma_{12}-1 / 2\left(\Gamma_{11}+\Gamma_{22}\right)\right],
$$

where $L$ is Avogadro's number, $Z$ is the nearest neighbour coordination number of the atom 1 or 2 , and $\Gamma_{i j}$ is the potential energy of interaction between the species $i$ and $j$. Here the term $Z$ represents the coordination number of an atom within its specific sublattice instead of the usual polyhedral coordination number around a central atom. For example, in the solid solution between $\mathrm{NaCl}$ and $\mathrm{KCl}$, each alkali atom has six nearest neighbour $\mathrm{Cl}$ atoms (and vice versa). However, in Equation 51, $Z$ must be taken as 12 , which represents the number of nearest neighbour alkali atoms surrounding a central alkali atom in the crystal structure. $W^{\mathrm{H}}$ in the simple mixture model is exactly the same as the interchange energy defined above. It should be noted that although Guggenheim neglected the effects of long range forces in the derivation Equation 51, inclusion of these forces leads to a similar expression (see Vinograd, 2001), except that the $Z[.$.$] term is replaced by \sum Z^{(k)}\left[\Gamma_{12}^{(k)}-1 / 2\left(\Gamma_{11}^{(k)}+\Gamma_{22}^{(k)}\right)\right]$, where the summation is carried out over $k$-nearest pairs (i.e. $1^{\text {st }}$ nearest, $2^{\text {nd }}$ nearest, $3^{\text {rd }}$ nearest, and so on). The contribution of the distant pairs may be important even though the energy of interaction may decrease rapidly with distance since $Z^{(k)}$ could increase rapidly with distance (Vinograd, pers. comm.).

In order to account for the mixing of molecules or atoms of different sizes, Guggenheim (1952) also introduced parameters known as contact factors, $q$, which represent the geometrical relation of an atom to another atom of different type in a nearest neighbour site. The contact factors have the property that $q_{1} / q_{2} \rightarrow 1$ as either contact factor tends to unity. (One can think of a number of relations between $q_{1}$ and $q_{2}$ that would satisfy this limiting property. For example, Green (1970a) assumed $q_{1} l q_{2}=1$, whereas Fei et al. (1986) assumed $q_{1}+q_{2}=1$. Both relations satisfy the required limiting behaviour of the ratio $q_{1} / q_{2}$.) Guggenheim (1952) showed that the deviation from a random distribution of the species is given by a parameter $\beta$, which is defined as

$$
\beta=\left\langle 1-4 \theta_{1} \theta_{2}\left[1-\exp \left(\frac{2 W}{Z R T}\right)\right]\right\rangle^{\frac{1}{2}},
$$

where $\theta$ is related to the contact factors according to

$$
\theta_{1}=1-\theta_{2}=\frac{X_{1} q_{1}}{X_{1} q_{1}+X_{2} q_{2}} .
$$

As the solution approaches a random distribution, i.e. $W / R T \rightarrow 0, \beta \rightarrow 1$, whereas for positive $(W>0)$ and negative $(W<0)$ deviations from ideality, $\beta>1$ and $<1$, respectively.

Within the above framework, Guggenheim (1952) derived the following QC expression for the molar excess Gibbs energy of mixing in a binary solution. 


$$
\frac{\Delta G_{\mathrm{m}}^{\mathrm{xs}}}{R T}=\frac{Z}{2}\left\{\left[\frac{X_{1} q_{1} \ln \left(\beta+\theta_{1}-\theta_{2}\right)}{\theta_{1}(\beta+1)}\right]+\left[\frac{X_{2} q_{2} \ln \left(\beta+\theta_{2}-\theta_{1}\right)}{\theta_{2}(\beta+1)}\right]\right\} .
$$

Using $H=\partial(G / T) / \partial(1 / T)$, one then has

$$
\Delta H_{\mathrm{m}}^{\mathrm{xs}}=\left[\frac{4 X_{1} X_{2} W}{\beta(\beta+1)}\right] \exp \left(\frac{2 W}{Z R T}\right) \cdot\left[\frac{X_{1} q_{1} \theta_{2}}{\beta+\theta_{1}-\theta_{2}}+\frac{X_{2} q_{2} \theta_{1}}{\beta+\theta_{2}-\theta_{1}}\right] .
$$

The $\Delta S_{\mathrm{m}}^{\mathrm{xs}}$ can be derived from the relation $G=H-T S$.

The unknown parameters, $q$ and $W$, for a binary system can be retrieved from phase equilibrium or enthalpy of mixing data, if the quasi-chemical model provides an adequate analytical representation of the data. From an analysis of $\mathrm{NaCl}-\mathrm{KCl}$ solvus data, Green (1970a) showed that $q_{\mathrm{Na}^{+}} / q_{\mathrm{K}^{+}}$nearly equals the ratio of the cationic radii or molar volumes of the two end members. However, Fei et al. (1986) failed to find any such relation between the ratio of the retrieved contact factors and molar volumes of the end members in the pyrope-grossular, diopside-Ca-Tschermak and diopside-enstatite solid solutions.

Modifications and extensions of the quasi-chemical theory have been suggested by Abrams \& Prausnitz (1975), Green (1970a), Powell (1983) and Pelton \& Blander (1986). The Abrams-Prausnitz modification, which is known as the universal quasichemical theory or UNIQUAC, involves only two adjustable parameters for a binary solution and seems to have a wide range of applicability for liquid solutions. Its success for solid solutions has not yet been tested. In the classic QC theory, the extrema in both enthalpy and entropy of mixing appearing for the negative deviation from ideality (which favours the formation of $1-2$ pairs) are at $X_{1}=X_{2}=0.5$, whereas such extrema often occur at other compositions in real systems. (In a binary system, $\Delta H^{\text {mix }}$ exhibits negative deviation from ideality with a " $V$ " shaped form, whereas $\Delta S^{\text {mix }}$ shows an inverted " $W$ " form in which the sagging of the central portion depends on the degree of ordering; see Vinograd, 2001, Fig. 11.) This problem with the location of extrema was remedied using a semi-empirical approach in the modification proposed by Pelton \& Blander (1986). Powell (1983) also discussed the incorporation of asymmetry in the QC formulation. Green (1970a), who was the first to apply QC model to mineralogical systems, developed an expression of $\Delta G^{\mathrm{xs}} / R T$ for the QC model as a power series of $W / R T$ and of a function of the contact factors. The simple mixture or the regular solution model follows in a straightforward way as a special case of Green's equation. It shows, as discussed by Ganguly \& Saxena (1987), that in order for the QC model to reduce to the simple mixture model, not only should $W / R T$ be small, but also the species 1 and 2 should be sufficiently alike in shape and size so that their contact factors, $q_{1}$ and $q_{2}$, are also similar. However, the magnitude of $W / R T$ and the dissimilarity of the contact factors must be intrinsically related in that $W / R T$ cannot be a small quantity unless the mixing units are sufficiently alike.

The simple mixture (or regular solution) and QC models follow as zeroth and first approximations, respectively, of a powerful approach developed by Kikuchi (1951), 
which is known as the cluster variation method. This method was applied by Burton \& Kikuchi (1984a, 1984b) to treat order-disorder in $\mathrm{CaCO}_{3}-\mathrm{MgCO}_{3}$ and $\mathrm{Fe}_{2} \mathrm{O}_{3}-\mathrm{FeTiO}_{3}$ solid solutions. An extended quasi-chemical model was developed by Truskinovskiy et al. (1987) to successfully treat order-disorder relations in a variety of mineral solid solutions. Vinograd (2001) discussed in detail the cluster variation method and applied it to garnet and pyroxene solid solutions.

\section{Athermal, Flory-Huggins, Wilson and NRTL (non-random two liquid) models}

The statistical thermodynamic study of Fowler \& Rushbrooke (1937) and calorimetric measurements of Meyer and co-workers (e.g. Meyer \& van der Wyk, 1944) showed that molecules of different size and shape mix with a significant non-random distribution or non-ideal entropy effect even when $\Delta H^{\mathrm{mix}}=0$. This type of solution is known as an athermal solution. Athermal behaviour is closely approximated, but not followed exactly, by several polymer solutions in which the components differ in size but have very similar energetic properties. However, as emphasised by Ganguly \& Saxena (1987), mineral solid solutions are not expected to show this type of behaviour as substitutions of atoms of different size invariably lead to nonideal enthalpic effects owing to the distortion of the lattice and nonlinear change in the bonding energies. However, athermal solutions offer a starting point for the development of models which have been successfully used to treat mineral solid solutions.

It was shown independently by Flory $(1941,1944)$ and Huggins $(1941)$ that the entropy of mixing resulting from the non-energetic solution of a polymer component (2) in a monomer solvent (1) is given by

$$
\Delta S_{\mathrm{m}}^{\mathrm{mix}}=-R\left(X_{1} \ln \Phi_{1}+X_{2} \ln \Phi_{2}\right),
$$

where $\Phi_{1}$ and $\Phi_{2}$ are the fraction of sites occupied by the solvent and the polymer, respectively. If there are $N_{1}$ molecules of the solvent and $N_{2}$ molecules of the polymer, and there are $p$ segments in a polymer molecule, then

$$
\Phi_{1}=\frac{N_{1}}{N_{1}+p N_{2}}, \Phi_{2}=\frac{p N_{2}}{N_{1}+p N_{2}},
$$

where $N_{1}+p N_{2}$ are the total number of sites in the solution. It is assumed that each lattice (or quasi-lattice) site is occupied by either a solvent molecule or a polymer segment. When a lattice site is occupied by a polymer segment, the adjacent sites are occupied by the rest of the segments so that each polymer molecule occupies $p$ lattice sites.

Wilson (1964) extended the Flory-Huggins formulation to include the mixing of molecules which differ not only in size but also in their energetic properties. This extension involved calculation of the relative probabilities of finding molecules of the two components around a central molecule or atom, say of the type $i$, taking into account the energies of interaction of the $i-j$ and $i-i$ pairs, and from that deriving expressions for the local volume fractions of the components around the central component. Wilson assumed that the ratio of the "local mole fractions" of the components $i$ and $j$ around a central component $i$ is given by 


$$
\frac{\chi_{j i}}{\chi_{i i}}=\frac{X_{j} \exp \left(-E_{j i} / R T\right)}{X_{i} \exp \left(-E_{i i} / R T\right)},
$$

where $\mathrm{E}_{i j}$ is the molar interaction energy between $i$ and $j$. The local volume fraction of a component around a central component of the same type is then given by

$$
\xi_{i}=\frac{V_{i} \chi_{i i}}{V_{i} \chi_{i i}+V_{j} \chi_{j i}},
$$

where $V_{i}$ and $V_{j}$ are the molar volumes of the components $i$ and $j$, respectively. Wilson used these local volume fractions in place of the overall site fractions in the Flory-Huggins expression (Eqn. 56). This procedure leads to

$$
\Delta G_{\mathrm{m}}^{\mathrm{xs}}=-R T\left[X_{1} \ln \left(X_{1}+\Lambda_{12} X_{2}\right)+X_{2} \ln \left(X_{2}+\Lambda_{21} X_{2}\right)\right]
$$

with

$$
\Lambda_{12}=\frac{V_{2}}{V_{1}} \exp \left[-\frac{E_{12}-E_{11}}{R T}\right]
$$

and

$$
\Lambda_{21}=\frac{V_{1}}{V_{2}} \exp \left[-\frac{E_{12}-E_{22}}{R T}\right]
$$

It should be noted that the local volume fractions in Wilson's formulation do not always add up to unity (Prausnitz et al., 1986). Also the Wilson expression has no rigorous theoretical justification, but is rather an intuitive extension of the Flory-Huggins formulation to account for the energetic effects on mixing. However, it has been successfully applied to many binary systems (Orye \& Prausnitz, 1965), and seems to have some appeal in the treatment of multicomponent solutions as discussed later. On the other hand, there are two important formal limitations of the Wilson expression (Wilson, 1964; Prausnitz et al., 1986). First, it cannot produce a maximum in the $\ln \gamma v s . X$ relation. Second, no values for the parameters $\Lambda_{12}$ and $\Lambda_{21}$ can be found that produce phase separation or unmixing, that is produce a 'hump' (or a convex upwards segment) in the $G_{\mathrm{m}} v s . X$ curve (which is always convex downwards near the terminal regions). In other words, there are no values of these parameters which satisfy the condition $\partial^{2} G_{\mathrm{m}} / \partial X_{i}^{2}<0$. Thus, if the solution has a miscibility gap, the application of the Wilson equation must be restricted to the $P-T-X$ domain where the solution is continuous.

Renon \& Prausnitz (1968) modified Wilson's formulation so that it can produce phase separation by introducing a correction factor, $\alpha_{12}$, as a multiplier of the energy terms in Equation 58. This model, which is known as the Non Random Two Liquid Model (NRTL), leads to the following expression for $\Delta G_{\mathrm{m}}^{\mathrm{xs}}$

$$
\Delta G_{\mathrm{m}}^{\mathrm{xs}}=X_{1} X_{2}\left[\frac{\left(E_{12}-E_{22}\right) G_{21}}{X_{1}+X_{2} G_{21}}+\frac{\left(E_{21}-E_{11}\right) G_{12}}{X_{2}+X_{1} G_{12}}\right] \text {, }
$$


where

$$
G_{i j}=\exp \left[-\frac{\alpha_{12}\left(E_{i j}-E_{j j}\right)}{R T}\right] .
$$

Expressions for the other thermodynamic excess functions can be derived from Equation 62, and are given in Prausnitz et al. (1986).

When $\alpha_{12}=0, G_{i j}=1$, and also the ratio of the local mole fraction reduces to that of the bulk mole fractions (Eqn. 58). Under this condition, the $\Delta G_{\mathrm{m}}^{\mathrm{xs}}$ in the $N R T L$ model reduces to

$$
\Delta G_{\mathrm{m}}^{\mathrm{xs}}=\Delta E\left(X_{1} X_{2}\right),
$$

where, using $E_{12}=E_{21}$,

$$
\Delta E=2 E_{12}-\left(E_{11}+E_{22}\right)
$$

Equation 64 is formally similar to the regular solution expression, Equation 33. However, $\Delta E$ reduces to the expression for $W$ in terms of pair potential energies, as given by Equation 51, only if $E_{i j}=Z / 2\left(L \Gamma_{i j}\right)$, where $Z$ is the number of nearest neighbours of the components $i$ and $j$ around a central component of $i$ or $j$. Thus, $E_{i j}$ should be treated as a quantity proportional to the pair potential energy between $i$ and $j$. By comparing the NRTL and QC models, Renon \& Prausnitz (1968) suggested that $\alpha_{12}$ should be similar to $1 / Z$. Consequently, $\alpha_{12}$ should be $<1$. However, as discussed later, the value of $\alpha$ retrieved from experimental mixing property data on mineral solid solutions sometimes depart very significantly from the expected value of $1 / Z$.

\section{Comparison of one-site binary mixing models}

Fei et al. (1986) applied the Guggenheim, Subregular, QC, Wilson and NRTL models to several binary mineral solid solutions for which calorimetric data for $\Delta H^{\text {mix }}$ were available. These are diopside-Ca-Tschermak (Di-CaTs), diopside-enstatite (Di-En), pyrope-grossular (Prp-Grs) and anorthite-albite (An-Ab) solid solutions. The Wilson equation was found to give a much worse fit to the data than the other models, whereas the Guggenheim polynomial using three constants, $A_{0}, A_{1}$ and $A_{2}$, had the best overall fit. The other three models also produced quite good fits to the data with the NRTL model giving a slightly better fit. The $\alpha$ value for the NRTL model varied between 0.05 and 0.30 , but did not show any correlation with the number of nearest neighbour cations around a central cation in a solid solution series. For example, in both Di-En and Prp-Grs solid solutions, each divalent cation has two nearest neighbour divalent cations. From the analysis of Renon \& Prausnitz (1968), as discussed above, the expected value of $\alpha$ is 0.50 , which is similar to the fitted value of 0.30 for the Prp-Grs solid solution, but much different from that for the Di-En solid solution, which is 0.05 .

Green (1970b) showed that while the phase diagram of the $\mathrm{NaCl}-\mathrm{KCl}$ solid solution may be fitted well by both subregular and quasichemical models, the retrieved thermodynamic properties from the two different models were quite different. The $\Delta H^{\mathrm{xs}}$ and $\Delta S^{\mathrm{xs}}$ values recovered from the fitted subregular parameters were much larger than the measured values, while those recovered from the fitted QC parameters were much 
closer to the latter. Thus, the success of fitting a limited amount phase equilibrium data by a given model does not guarantee that the extracted thermodynamic mixing properties are correct. One must simultaneously treat as large a data set as available, and also evaluate if the theoretical basis of the model is appropriate for the specific solid solution being modelled. Thus, for example, although the NRTL model provides a good fit to the $\Delta H^{\mathrm{xs}}$ data for the Di-En solid solution, the fact that the retrieved value is grossly different from the value expected from theory may be a warning about the inadequacy of the NRTL model for this solid solution.

\section{Multicomponent solutions}

An important practical problem in solution thermodynamics lies in the formulation of the method of prediction of the properties of multicomponent solutions from those of the bounding binaries. The problem has been discussed by a number of workers earlier (e.g. Jiran \& Jacob, 1983; Hillert, 1980, 1998; Cheng \& Ganguly, 1994) to which the interested reader should refer for more extensive discussions. There have been two common approaches in the development of multicomponent excess Gibbs energy models. One is to begin with an appropriate polynomial function to represent $\Delta G_{\mathrm{m}}^{\mathrm{xs}}$ of the multicomponent solution, and then truncate it after a certain number of terms, which leads to special forms for $\Delta G_{\mathrm{m}}^{\mathrm{xs}}$ for the bounding binaries. The other approach is to combine the binary excess free energies according to certain empirical schemes. These approaches, which have been called respectively the "power series multicomponent models" and "projected multicomponent models" by Cheng \& Ganguly (1994), are discussed below.

I will refer to a multicomponent solution by the nature of its most asymmetric binary. For example, a subregular multicomponent solution is the one for which the most asymmetric binary has subregular behaviour. I will first discuss solution models which deal with mixing within a single structural site, and then a method of combination of mixing within the individual sites to express the multisite mixing properties.

\section{Power series multicomponent models}

One of the earliest and most successful multicomponent models is that due to Wohl $(1946,1953)$, who introduced a power series expression for $\Delta G_{\mathrm{m}}^{\mathrm{xs}}$ of a ternary solution. Wohl's ternary expression is as follows

$$
\Delta G_{\mathrm{m}}^{\mathrm{xs}}=\sum_{i \neq j} X_{i} X_{j}\left(W_{i j}^{\mathrm{G}} X_{j}+W_{j i}^{\mathrm{G}} X_{i}\right)+X_{i} X_{j} X_{k}\left[\frac{1}{2} \sum_{i \neq j}\left(W_{i j}+W_{j i}\right)+C_{i j k}\right] .
$$

Subsequently, power series ternary and quaternary expressions were developed by several workers in the geochemical literature, viz. Anderson \& Lindsley (1981), Berman \& Brown (1984), Helffrich \& Wood (1989) and Mukhopadhyay et al. (1993). However, Cheng \& Ganguly (1994) showed that all these expressions are either equivalent to Wohl's ternary expression or represent its extension to quaternary solution. They also developed a power series quaternary expression following Wohl's ternary formulation, 
and showed that upon truncating it after the third degree terms (i.e. those that contain three-suffix constants reflecting three-component interactions), the excess Gibbs energy of mixing can be expressed as

$$
\Delta G_{\mathrm{m}}^{\mathrm{xs}}=\sum_{i \neq j} X_{i} X_{j}\left(W_{i j}^{\mathrm{G}} X_{j i}+W_{j i}^{\mathrm{G}} X_{i j}\right)+\sum_{i \neq j, \neq k} X_{i} X_{j} X_{k} C_{i j k},
$$

where $C_{i j k}$ is a ternary interaction term, as defined below, the $W^{\mathrm{G}}$-s are the binary interaction parameters, and $X_{j i}$ and $X_{i j}$ are the projected mole fractions of the components $j$ and $i$, respectively, in the binary join $i-j$. These binary mole fractions are obtained by the normal projection of the multicomponent composition onto that join. Analytically, $X_{i j}$ is given by $1 / 2\left(1+X_{i}-X_{j}\right)$. It is interesting to note that the first right hand term in the above expression represents a summation of $\Delta G_{\mathrm{m}}^{\mathrm{xs}}$ of the subregular bounding binaries at compositions that are at the shortest distance from the multicomponent composition. Furthermore, a quaternary or higher order solution does not involve a quaternary or higher order term when the binaries have sub-regular behaviour (this conclusion was also independently reached by Jordan et al., 1950; Helffrich \& Wood, 1989; and Mukhopadhyay et al., 1993). Using Equations 67 and 15, one can obtain the expression for the activity coefficient of a component in a multicomponent subregular solution (see Cheng \& Ganguly, 1994).

In terms of the coefficients of the power series expression, the binary subregular parameters are given by (Wohl, 1946; Cheng \& Ganguly, 1994)

$$
W_{i j}=a_{i j}+a_{i i j} \text { and } W_{j i}=a_{i j}+a_{i j j} \text {, }
$$

whereas the ternary term represents

$$
C_{i j k}=1 / 2\left(2 a_{i j k}-a_{i j}-a_{i j j}-a_{i i k}-a_{i k k}-a_{i j k}-a_{j k k}\right) .
$$

Here the ' $a$ ' terms are related to the interactions of the subscripted species. Now, if $a_{i i j}=a_{i j j}$, then $W_{i j}=W_{j i}$, and consequently the first right hand term of Equation 67 reduces to a combination of binary excess free energies with regular solution behaviour. However, under this condition, that is the equivalence of three body interactions between two species, $C_{i j k}=\left[a_{i j k}-\left(a_{i j}+a_{i i k}+a_{j j k}\right)\right]$, which is not necessarily equal to zero. Thus, in general, $\Delta G_{\mathrm{m}}^{\mathrm{xs}}$ of a ternary or higher order regular solution may not equal that obtained by the summation of the subsidiary binaries. However, it is likely that when the binaries conform to a regular solution, the $C_{i j k}$ terms are small. This is an intuitive suggestion in the sense that a ternary regular solution should involve a smaller number of higher order terms than a ternary subregular solution.

[It should be noted that the so-called ternary term of Berman \& Brown (1984) is not the ternary interaction term $C_{i j k}$ defined above, which we will call $C_{i j k}($ Wohl), but represents the first term within the square bracket of Equation 66, that is one-half of the sum of the binary interaction terms. The $C_{i j k}$ term of Mukhopadhyay et al. (1993) is also not the $C_{i j k}($ Wohl), but stands for the collection of terms within the square brackets of Equation 66. Also note that their $W_{i j k}=-C_{i j k}($ Wohl $)$.] 
Redlich \& Kister (1948) utilised Guggenheim's polynomial for binary solution (Eqn. 31) to express $\Delta G_{\mathrm{m}}^{\mathrm{xs}}$ of multicomponent solution. Their expression, which is commonly referred to as the Redlich-Kister model, involves summation of the binary $\Delta G_{\mathrm{m}}^{\mathrm{xs}}$ plus multicomponent correction terms, i.e.

$$
\Delta G_{\mathrm{m}}^{\mathrm{xs}}=\sum X_{i} X_{j}\left(\Delta G_{\mathrm{m}}^{\mathrm{xs}}\right)_{i j}+\text { multicomponent correction terms, }
$$

where $\left(\Delta G_{\mathrm{m}}^{\mathrm{xs}}\right)_{i j}$ is calculated at $X_{i}$ and $X_{j}$ from Equation 40 (note that these are total atomic or mole fractions of the components in the multicomponent system). The Redlich-Kister model has enjoyed popularity in the metallurgical literature (e.g. Hillert, 1998). However, it should be noted that it is equivalent to the Wohl model as long as the bounding binaries follow regular or subregular behaviour (Cheng \& Ganguly, 1994), i.e. when the constant terms higher than $A_{1}$ are zero in the polynomial expression of the binary excess free energies (Eqn. 31 ).

\section{Projected multicomponent models}

Several schemes have been proposed for combining the binaries to predict the multicomponent behaviour with or without involving multicomponent interaction terms. These methods, which are due to Kohler (1960), Colinet (1967), Muggianu et al. (1975) and Bonnier \& Caboz (1965, quoted in Hillert, 1998), are illustrated in Figure 4. Their expressions for the $\Delta G_{\mathrm{m}}^{\mathrm{xs}}$ in a ternary solution have been summarised by Hillert (1998), and are, thus, not repeated here. The method of shortest distance suggested by Muggianu et al. (1975), which is usually referred to as the Muggianu method, was also suggested independently by Jacob \& Fitzner (1977). We will, thus, refer to this model as the Muggianu-Jacob model. The expression for $\Delta G_{\mathrm{m}}^{\mathrm{xs}}$ given by Bonnier \& Caboz

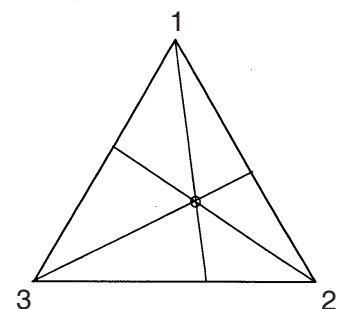

(a) Kohler

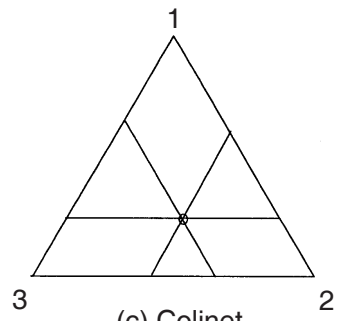

(c) Colinet

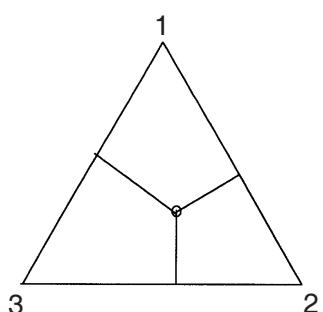

(b) Muggianu-Jacob

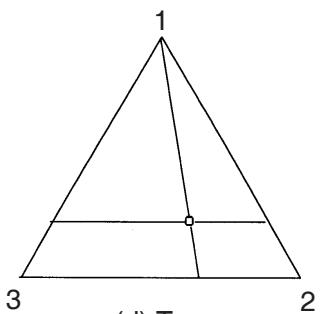

(d) Toop

Fig. 4. Schematic illustration of the "Projected Multicomponent Models" for a ternary system. The $\Delta G_{\mathrm{m}}^{\mathrm{xs}}$ of a ternary solution is calculated by combining the $G_{\mathrm{m}}^{\mathrm{xs}}$ of the terminal binaries at the projected compositions. 
(1965) was modified later by Toop (1965) in order that the ternary $\Delta G_{\mathrm{m}}^{\mathrm{xs}}$ appears as a summation of the $\Delta G_{\mathrm{m}}^{\mathrm{xs}}$ in the binaries when the latter have regular solution behaviour, i.e. $\Delta G_{\mathrm{m}}^{\mathrm{xs}}($ ternary $)=\sum X_{i j} X_{j i} \Delta\left(G_{\mathrm{m}}^{\mathrm{xs}}\right)_{i j}$ where $X_{i j}$ and $X_{j i}$ are the shortest distance binary compositions from the ternary compositional point. The modified Bonnier-Caboz formulation is often referred to as Toop's method in the literature. The primary motivations behind the different projected multicomponent formulations is the prediction of the multicomponent behaviour from only the binary properties, that is to somehow 'absorb' the effects of multicomponent interactions within the scheme of combination of the binaries.

Toop's method is an asymmetric formulation in that it treats one component (component 1 in Fig. 4d) differently from the other two. Thus, this method ought to be applied only to ternary systems where one component has a distinctly different property from the other two. For example, Pelton \& Blander (1986) used a modified QC formulation for the silicate slag system $\mathrm{SiO}_{2}-\mathrm{CaO}-\mathrm{FeO}$ in which the method of combination of binaries is analogous to that of Toop's method. They chose $\mathrm{SiO}_{2}$ as the special component 1 , since it is an acidic component while the other two are basic components. The predicted ternary properties from combination of the binary data were found to be in good agreement with the experimental data. For solid solutions, one may also be able to identify a component which behaves quite differently from the others. For example, in aluminosilicate garnet, $(\mathrm{Fe}, \mathrm{Mg}, \mathrm{Ca})_{3} \mathrm{Al}_{2} \mathrm{Si}_{3} \mathrm{O}_{12}, \mathrm{Ca}$ is the most nonideally mixing component, while $\mathrm{Fe}$ and $\mathrm{Mg}$ mix nearly ideally (e.g. Ganguly et al., 1996). Thus, Ca may be treated as the unique component in the asymmetric formulation.

The expression of $\Delta G_{\mathrm{m}}^{\mathrm{xs}}$ obtained for a multicomponent subregular solution (Eqn. 67) using the power series approach of Wohl (1946) involves a combination of binary excess Gibbs energies at compositions that are at the shortest distance from the multicomponent composition. This is exactly the method of combination of the binaries suggested in the Muggianu-Jacob projected multicomponent model (Fig. 4b). Thus, there seems to be an independent theoretical justification in the scheme of the combination of binaries in this model. It was found (Jacob \& Fitzner, 1977; Jacob, pers. comm.) that for metallic systems the shortest distance method predicts the ternary $\Delta G_{\mathrm{m}}^{\mathrm{xs}}$ somewhat better than the other methods. However, the quality of agreement between the predicted and measured ternary values becomes worse with increasing non-ideality of the binaries, especially when a binary $\Delta G_{\mathrm{m}}^{\mathrm{xs}}$ exceeds $15 \mathrm{~kJ} / \mathrm{mole}$, implying increasing importance of the higher order terms.

\section{Estimation of higher order interaction terms}

In principle, it is impossible to determine the multicomponent interaction terms from only the binary data. The higher order interactions specific to a given model can only be determined from comparison of the predicted multicomponent behaviour from the binary data with the multicomponent properties determined experimentally. It is, however, doubtful if experimental data are going to be sufficient for such purpose in the foreseeable future, at least for systems of geological interests. A viable alternative would be to determine the binary and multicomponent enthalpic properties from the 
crystallographic data and pair potential energies of the ions participating in the solid solutions (e.g. Ottonello, 1992). Since there are a large body of crystallographic data for a variety of rock-forming mineral solid solutions in both binary and multicomponent systems, it may be possible to use this approach to at least approximately evaluate the relative magnitudes of the higher order terms in the different multicomponent formulations. One may, thus, determine the effectiveness of the different approaches in predicting the multicomponent behaviour from only binary data.

From theoretical analysis, Cheng \& Ganguly (1994) developed a method of approximation of the $C_{i j k}$ term (Eqn. 67) in the special case that one of the binaries, $j-k$, behaves nearly ideally. Ilmenite series, $(\mathrm{Mg}, \mathrm{Fe}, \mathrm{Mn}) \mathrm{TiO}_{3}$, and garnet series, $(\mathrm{Ca}, \mathrm{Fe}, \mathrm{Mg})_{3} \mathrm{Al}_{2} \mathrm{Si}_{3} \mathrm{O}_{12}$, are examples of this type of solid solution. In both cases, the last two components mix nearly ideally (Shibue, 1999; Ganguly et al., 1996). Indeed, $\mathrm{Fe}^{2+}$ and $\mathrm{Mg}$ mix with small deviation from ideality in all ferromagnesian silicates for which the thermodynamic mixing properties are known (Ganguly \& Saxena, 1987). Thus, this approximation scheme should be applicable to ternary joins of rock-forming minerals involving $\mathrm{Fe}^{2+}-\mathrm{Mg}$ as one of the subsidiary binaries. The method is as follows.

$$
C_{i j k} \approx \sum \sigma_{i j} \sigma_{i k}\left[\left(W_{i j}-W_{j i}\right) \frac{X_{j}}{X_{j}+X_{k}}+\left(W_{i k}-W_{k i}\right) \frac{X_{k}}{X_{j}+X_{k}}\right],
$$

where $\sigma_{i j}=0$ when $i=j$, and $\sigma_{i j}=1$ when $i \neq j$. For garnet, this method predicts $C_{\mathrm{CaMgFe}}$ to be of the order of a kJ per cation-mole of the ternary garnet solid solution. This is consistent with the conclusion of Berman \& Koziol (1991), based on the analysis of natural and experimental phase equilibrium data involving garnet solid solutions.

\section{Multicomponent property without multicomponent terms}

The Wilson, NRTL, QC and UNIQUAC formulations have been extended to multicomponent solutions without requiring any multicomponent term. These extensions, which can be found in Prausnitz et al. (1986) and Pelton \& Blander (1986), have special appeal in that the calculation of the multicomponent properties requires knowledge of only the binary properties. However, it remains to be tested how well these formulations predict the behaviour of multicomponent silicate and oxide solid solutions.

Using only the binary mixing parameters, Shibue (1999) applied both the ternary Wilson and Margules (which is the same as Wohl's) formulations to the $(\mathrm{Fe}, \mathrm{Mn}, \mathrm{Mg}) \mathrm{TiO}_{3}$ solid solution to evaluate which one predicts the behaviour of the ternary solution better. He utilised the data on cation exchange between aqueous chloride solution and the three binary solid solutions in this system to derive binary cation mixing properties in the solid solution, assuming the chloride solution to be ideal. Of the three binaries, the $\mathrm{Fe}^{2+}-\mathrm{Mn}^{2+}$ join was found to be nearly ideal. From the retrieved binary mixing data, Shibue (1999) calculated the ternary mixing properties, and from them the compositions of aqueous chloride solutions in equilibrium with ternary solid solutions of various compositions. The predicted compositions of the chloride solution were then compared with the experimental data of Kubo et al. (1992) on the equilibrium compositions of coexisting solid and chloride solution. Shibue (1999) found that the sum of the distances $\left(\sum d_{i}\right)$ 
between the predicted and observed ternary chloride solution using Wilson's formulation for the solid solution is 0.0094 , compared to that of 0.0127 using Wohl's formulation with only the binary terms. He, thus, concluded that the prediction of ternary behaviour from the Wilson formulation is better than that from Wohl's formulation. However, incorporation of the ternary parameter in Wohl's formulation according to Equation 71, which can be calculated from the binary data, leads to very similar quality of prediction of the ternary property as that obtained from the Wilson formulation (Shibue, pers. comm.).

One problem with the above analysis of the relative merits of the two models is that the values of $\Delta G^{0}$ of the binary solid-fluid exchange reactions that are retrieved from the experimental data depend on the adopted binary mixing models for the solids. However, in principle, $\Delta G^{0}$ is a unique quantity. In addition, the retrieved values of $\Delta G^{0}$ depend on whether the sum of the values for the three binaries have been constrained to be zero, as there are only two independent binaries, or whether these are derived solely from the best fit to the binary data. The resultant variation of $\Delta G^{0}$ leads to changes of the correlated binary parameters and, hence, in the quality of prediction of ternary properties. For example, the subregular parameters retrieved from the constraint that $\sum \Delta G^{0}$ (binaries) $=0$ are somewhat different from those that are derived simply from best fits to the binary data, and used in Shibue (1999). The first set leads to a poorer prediction of the ternary properties $\left(\sum d_{i}=0.0154\right)$ compared to those from the second set $\left(\sum d_{i}=0.0099\right)$ (Shibue, pers. comm.).

Barron (1976) compared the predictive success of the ternary properties in the system $\mathrm{Ab}-\mathrm{Kfs}-\mathrm{An}$ at $900{ }^{\circ} \mathrm{C}$ according to Wohl's and Kohler's model using only the binary terms. In this ternary system, there is a large solvus in the An-Kfs binary, and continuous solid solution in the two other joins at $900{ }^{\circ} \mathrm{C}$. Both models predict the experimentally determined ternary solvus at $900{ }^{\circ} \mathrm{C}$ quite closely. Ottonello (1992) also found that Wohl's and Kohler's models have comparable predictive abilities of ternary properties from the binary data.

\section{Solid solutions with multi-site mixing}

Hillert (1998) suggested the following expression to represent the $\Delta G_{\mathrm{m}}^{\mathrm{xs}}$ of a two-site binary reciprocal solution, ${ }^{\mathrm{I}}(A, B)_{b}{ }^{\mathrm{II}}(C, D)$, for which $\Delta G_{\mathrm{m}}$ is given by Equation 16 .

$$
\Delta G_{\mathrm{m}}^{\mathrm{xs}}=\chi_{\mathrm{A}} \chi_{\mathrm{B}} \chi_{\mathrm{C}} I_{\mathrm{AB}: \mathrm{C}}+\chi_{\mathrm{A}} \chi_{\mathrm{B}} \chi_{\mathrm{D}} I_{\mathrm{AB}: \mathrm{D}}+\chi_{\mathrm{C}} \chi_{\mathrm{D}} \chi_{\mathrm{A}} I_{\mathrm{CD}: \mathrm{A}}+\chi_{\mathrm{C}} \chi_{\mathrm{D}} \chi_{\mathrm{B}} I_{\mathrm{CD}: \mathrm{B}},
$$

where $\chi_{\mathrm{A}}$ is the atomic fraction of the species $A$ in the site $\mathrm{I}, I_{\mathrm{AB}: \mathrm{C}}$ is the interaction parameter between $A$ and $B$ in the site I when site II is completely filled by $C, I_{\mathrm{CD}: \mathrm{A}}$ is the interaction parameter between $C$ and $D$ in the site II when site I is completely is filled by $A$, and so on. The above expression allows different behaviour of $\Delta G_{\mathrm{m}}^{\mathrm{xs}}$ within a specific sublattice depending on the nature of the species occupying the other sublattice, or in other words, different $\Delta G_{\mathrm{m}}^{\mathrm{xs}}$ on opposite sides of the compositional square illustrated in Figure 1. For example, when $\chi_{\mathrm{C}}=1, \Delta G^{\mathrm{xs}}=\chi_{\mathrm{A}} \chi_{\mathrm{B}} I_{\mathrm{AB}: \mathrm{C}}$, but when $\chi_{\mathrm{D}}=1, \Delta G^{\mathrm{xs}}=\chi_{\mathrm{A}} \chi_{\mathrm{B}} I_{\mathrm{AB}: \mathrm{D}}$. Each site parameter, $I_{\mathrm{AB}: \mathrm{C}}$ and so on, may be expressed according to the Guggenheim or the so-called Redlich-Kister form, that is, by the expression within the square bracket in Equation 31, truncating it after the appropriate number of terms, as demanded by the data. Extensions of 
this approach to multiple sublattices and multiple components have been discussed by Hillert (1998) (and is incorporated in the commercial computer program Thermo-Calc: http://www/thermocalc.se, which has been used extensively for the calculation of phase diagrams).

\section{Concluding remarks}

I have summarised above the physical ideas and the basic theoretical structure for a variety of solution models that have been used to treat the thermodynamic properties of mineral solid solutions. These models are also applicable to melts. It may be possible to fit a limited body of data by more than one-solution models equally well, but $\Delta H^{\text {mix }}$ and $\Delta S^{\text {mix }}$ predicted by the different models could differ quite significantly. It is, therefore, important to examine the theoretical basis of the solution models in such cases and to ensure, as much as possible, compatibility of the adopted solution model with the known microscopic properties of the solid solution (e.g. short range ordering; compatibility of the retrieved fitting parameters with their expected values from theory such as discussed in the section on "comparison of one-site binary mixing models").

From the results of the comparative studies, as discussed above, Guggenheim's polynomial (Eqn. 31) or the so-called Redlich-Kister formulation seems to offer a simple and flexible model for binary solid solutions, although in some specific cases another model, especially QC model when there is short range order, may work better. Use of the Guggenheim polynomial for the binaries affords an additional advantage in the treatment of reciprocal solid solutions in terms of the form suggested by Hillert (1998), because the $\Delta G_{\mathrm{m}}^{\mathrm{xs}}$ in this expression reduces to the form $\chi_{i} \chi_{j}[.$.$] for the terminal binaries. Binary$ solutions obeying DQF can also be incorporated in this scheme by defining a solution between a real component and a hypothetical component (Eqn. 43). Finally, if one is to use only the binary terms to predict the multicomponent properties, then the "shortest distance method" of combining the binaries (Fig. 4c) is probably the overall best method because of the theoretical justification, as discussed above. The asymmetric Toop method could be advantageous where there is a component with a distinctly different property.

There is currently a great paucity of experimental data on the multicomponent mixing properties of rock-forming minerals which have been routinely used for thermobarometric and other phase equilibrium calculations. These types of data are needed to understand the nature of the higher order terms and the method of combination of binaries to predict the multicomponent properties from the binary data. In many important systems, adequate binary data are also lacking. The lack of sufficient wellconstrained experimental data has led to a proliferation of empirically adjusted formulations of a given geothermometer or a geobarometer. An example is the garnet-biotite $\mathrm{Fe}^{2+}-\mathrm{Mg}$ exchange thermometer, for which there are approximately 20 different empirical or semi-formulations to take into account the nonideal mixing effects of additional components, especially in biotite.

With the advancement of diffusion kinetic modelling of compositional zoning of rock-forming minerals, such as garnet and pyroxene, to retrieve the time scales of metamorphic processes (e.g. Spear, 1995; Ganguly et al., 2000) there is now an 
increased need for accurate thermometric formulations. This is because of the exponential dependence of the diffusion process on temperature $(D \propto \exp (-Q / R T))$, so that a small error in temperature estimate translates into a large error in the retrieved time scales. The problem is especially acute in minerals such as garnet and pyroxene, which have a relatively large activation energy, $Q$, of diffusion (Ganguly \& Tazzoli, 1994; Ganguly et al., 1998). In addition, resolution of many large-scale tectono-metamorphic problems relies on the precision of thermo-barometers from which a spatial distribution map of $P-T$ conditions of metamorphism is produced (e.g. Neogi et al., 1998). The extraction of thermodynamic properties of silicate melts, which have wide ranging applications, from solid-melt phase equilibrium data requires reliable data on the thermodynamic properties of the solid solutions. Mutual compatibility of the thermodynamic properties of the melt and solid phases is necessary, but not sufficient, for the successful prediction of melt properties beyond the range of experimental phase equilibrium data from which these were extracted.

In view of the wide ranging applications of thermodynamic properties of solid solutions to geological problems, it is hoped that there will be a major effort to provide experimental data that would tightly constrain the properties of multicomponent rockforming minerals and lead to improvements in the theoretical formulations relating the binary and multicomponent properties. However, because of their compositional complexity, it may be a long time before we have adequate experimental data to sufficiently constrain the thermodynamic properties of some important mineral solid solutions. It is, therefore, necessary to improve our understanding of the microscopic basis of thermodynamic nonideality of solid solutions so we can make appropriate approximations where adequate experimental data are not available. A microscopic understanding is also important to evaluate the quality of, and discriminate among, conflicting experimental results.

\section{Acknowledgements}

I am indebted to Prof. Mats Hillert for a thorough and constructive review of an earlier version of the manuscript in a very short notice. Thanks are due to Prof. Charles Geiger and Prof. Sumit Chakraborty for their suggestions to improve the clarity of presentation and to Dr. Victor Vinograd and Prof. Yasuhiro Shibue for helpful discussions. Prof. Geiger's careful editorial work is also gratefully appreciated. I, of course, bear the sole responsibility of any error or lack of clarity that still exists in this paper. This work was partly supported by a NASA grant No. NAG 5-7364.

\section{References}

Abrams, D.S. \& Prausnitz, J.M. (1975): Statistical thermodynamics of liquid mixtures: A new expression for the excess Gibbs energy of partly or completely miscible systems. Am. Inst. Chem. Eng. J., 21:116-128.

Anderson, D.J. \& Lindsley, D.H. (1981): A valid Margules formulation for an asymmetric ternary solution: Revision of olivine-ilmenite thermometer, with applications. Geochim. Cosmochim. Acta, 45:847-853.

Andersson, J.-O., Fernández Gillermet, A., Hillert, M., Jansson, B. \& Sundman, B. (1986): A compound energy model of ordering in a phase with sites of different coordination numbers. Acta Metall., 34:437-445.

Barron, L.M. (1976): A comparison of two models of ternary excess free energy. Contrib. Mineral. Petrol., 57:71-81. 
Berman, R.G. \& Brown, T.H. (1984): A thermodynamic model for multicomponent melts, with applications to the system $\mathrm{CaO}-\mathrm{Al}_{2} \mathrm{O}_{3}-\mathrm{SiO}_{2}$. Geochim. Cosmochim. Acta, 48:661-678.

Berman, R.G. \& Koziol, A.M. (1991): Ternary excess properties of grossular-pyrope-almandine garnet and their influence in geothermometry. Am. Mineral., 76:1223-1231.

Blander, M. (1964): Thermodynamic properties of molten salt solutions. In Blander, M. (ed.): Molten salt chemistry. New York (N.Y.): Wiley, 127-237.

Bosenick, A. \& Geiger, C.A. (1997): Powder X-ray diffraction study of synthetic pyrope-grossular garnets between 20 and $295 \mathrm{~K}$ : a comparison of thermal expansion and heat capacity and volumes of mixing. $J$. Geophys. Res., 102:22,649-22,657.

Burton, B. \& Kikuchi, R. (1984a): Thermodynamic analysis of the system $\mathrm{CaCO}_{3}-\mathrm{MgCO}_{3}$ in the tetrahedron approximation of the cluster variation method. Am. Mineral., 69:165-175.

Burton, B. \& Kikuchi, R. (1984b): The antiferromagnetic-paramagnetic transition in $\alpha-\mathrm{Fe}_{2} \mathrm{O}_{3}$ in the single prism approximation of the cluster variation method. Phys. Chem. Miner., 11:125-131.

Cheng, W. \& Ganguly, J. (1994): Some aspects of multicomponent excess free energy models with subregular binaries. Geochim. Cosmochim. Acta, 58:3763-3767.

Colinet, C. (1967): Relation between the geometry of ternary phase diagrams and the thermodynamic properties of liquid solutions. Diplôme d'études supérieures, Univ. Grenoble, France. (PhD Thesis, in French)

Darken, L.S. (1950): Application of the Gibbs-Duhem equation to ternary and multicomponent systems. J. Am. Chem. Soc., 72:2909-2914.

Darken, L.S. (1967): Thermodynamics of binary metallic solutions. Met. Soc. AIME Trans., 239:80-89.

Darken, L.S. \& Gurry, R.W. (1953): Physical chemistry of metals. New York (N.Y.): McGraw-Hill.

Evans, B.W. \& Frost, B.R. (1975): Chrome-spinel in progressive metamorphism - a preliminary analysis. Geochim. Cosmochim. Acta, 39:959-972.

Fei, Y., Saxena, S.K. \& Eriksson, G. (1986): Some binary and ternary silicate solid solution models. Contrib. Mineral. Petrol., 94:221-229.

Flood, H., Førland, T. \& Grjotheim, K. (1954): Über den Zusammenhang zwischen Konzentration und Aktivitäten in geschmolzenen Salzmischungen. Z. Anorg. Allg. Chem., 276:290-315.

Flory, P.J. (1941): Thermodynamics of high polymer solutions. J. Chem. Phys., 9:660-661.

Flory, P.J. (1944): Thermodynamics of heterogeneous polymers and their solutions. J. Chem. Phys., 12:425-438.

Førland, T. (1964): Thermodynamic properties of fused salt systems. In Sundheim, B.R. (ed.): Fused salts. New York (N.Y.): McGraw-Hill, 63-164.

Fowler, R.H. \& Rushbrooke, G.S. (1937): An attempt to extend the statistical theory of perfect solutions. Trans. Faraday Soc., 33:1272-1294.

Ganguly, J. (1982): Mg-Fe order-disorder in ferromagnesian silicates. II. Thermodynamics, kinetics, and geological applications. In Saxena, S.K. (ed.): Advances in physical geochemistry, Vol. 2. Berlin-HeidelbergNew York (N.Y.): Springer-Verlag, 58-99.

Ganguly, J. \& Saxena, S.K. (1987): Mixtures and mineral reactions. Berlin-Heidelberg-New York (N.Y.): Springer-Verlag.

Ganguly, J. \& Tazzoli, V. (1994): $\mathrm{Fe}^{2+}-\mathrm{Mg}$ interdiffusion in orthopyroxene: Retrieval from the data on intracrystalline exchange reaction. Am. Mineral., 79:930-937.

Ganguly, J., Cheng, W. \& O’Neill, H.St.C. (1993): Syntheses, volume, and structural changes of garnets in the pyrope-grossular join: Implications for stability and mixing properties. Am. Mineral., 78:583-593.

Ganguly, J., Cheng, W. \& Tirone, M. (1996): Thermodynamics of aluminosilicate garnet solid solution: new experimental data, an optimized model, and thermometric applications. Contrib. Mineral. Petrol., 126:137-151.

Ganguly, J., Cheng, W. \& Chakraborty, S. (1998): Cation diffusion in aluminosilicate garnets: experimental determination in pyrope-almandine diffusion couples. Contrib. Mineral. Petrol., 131:171-180.

Ganguly, J., Dasgupta, S., Cheng, W. \& Neogi, S. (2000): Exhumation history of a section of the Sikkim Himalayas, India: records in the metamorphic mineral equilibria and compositional zoning of garnet. Earth Planet. Sci. Lett., 183:471-486.

Ghiorso, M. (1990): Application of the Darken equation to mineral solid solutions with variable degrees of orderdisorder. Am. Mineral., 75:539-543. 
Ghose, S. (1982): Mg-Fe order-disorder in ferromagnesian silicates. I. Crystal Chemistry. In Saxena, S.K. (ed.): Advances in physical geochemistry, Vol. 2. Berlin-Heidelberg-New York (N.Y.): Springer-Verlag, 4-57.

Green, E.J. (1970a): Predictive thermodynamic models for mineral systems. I. Quasi-chemical analysis of the halite-sylvite subsolidus. Am. Mineral., 55:1692-1713.

Green, E.J. (1970b): Perils of thermodynamic modelling. Geochim. Cosmochim. Acta, 34:1029-1033.

Guggenheim, E.A. (1937): Theoretical basis of Raoult's law. Trans. Faraday Soc., 33:151-159.

Guggenheim, E.A. (1952): Mixtures. Oxford: Clarendon Press.

Guggenheim, E.A. (1967): Thermodynamics. Amsterdam: North Holland Publ. Co.

Helffrich, G. \& Wood, B.J. (1989): Subregular models for multicomponent solutions. Am. Mineral., 74:1016-1022.

Hildebrand, J.H. (1929): Solubility, XII, Regular solutions. J. Am. Chem. Soc., 51:66-80

Hillert, M. (1980): Empirical methods of predicting and representing thermodynamic properties of ternary solution phases. Calphad, 4:1-12.

Hillert, M. (1998): Phase equilibria, phase diagrams and phase transformations: Their thermodynamic basis. Cambridge (U.K.): Cambridge Univ. Press.

Hillert, M. \& Staffansson, L.-I. (1970): Regular solution model for stoichiometric phases and ionic melts. Acta Chem. Scand., 24:3618-3626.

Huggins, M.L. (1941): Solutions of long chain compounds. J. Phys. Chem., 9:440.

Jacob, K.T. \& Fitzner, K. (1977): The estimation of the thermodynamic properties of ternary alloys from binary data using the shortest distance composition path. Thermochim. Acta, 18:197-206.

Jiran, E. \& Jacob, K.T. (1983): Computation of the thermodynamic properties of quaternary and higher order systems from binary data using shortest distance composition paths. Calphad, 7:41-50.

Jordan, D., Gerster, J.A., Colburn, A.P., \& Wohl, K. (1950): Vapor-liquid equilibrium of $\mathrm{C}_{4}$ hydrocarbon-furfuralwater mixtures. Chem. Eng. Prog., 46:601-613.

Kikuchi, R. (1951): A theory of cooperative phenomena. Phys. Rev., 81:988-1003.

Kohler, F. (1960): Zur Berechnung der thermodynamischen Daten eines ternären Systems aus dem zugehöringen binären System. Monatsh. Chem., 91:738-740.

Kroll, H., Schiemann, I. \& von Cölln, G. (1986): Feldspar solid solutions. Am. Mineral., 71:1-16.

Kubo, T., Uchida, E., Furukawa, Y. \& Imai, N. (1992): Experimental study on ion exchange equilibria between solid solution $\left(\mathrm{Fe}^{2+}, \mathrm{Mn}^{2+}, \mathrm{Mg}^{2+}\right) \mathrm{TiO}_{3}$ and aqueous $\left(\mathrm{Fe}^{2+}, \mathrm{Mn}^{2+}, \mathrm{Mg}^{2+}\right) \mathrm{Cl}_{2}$ solution. Kobutsugaku Zasshi (J. Mineral. Soc. Jpn.), 21:59-67 (in Japanese with English abstract).

Liermann, H-P. \& Ganguly, J. (1999): Thermodynamics and kinetics of $\mathrm{Fe}^{2+}-\mathrm{Mg}$ exchange between spinel and orthopyroxene: Experimental determination an application to cooling rates (abstract). Meteorit. Planet. Sci., 34 (suppl.): A75.

Meyer, K.H. \& van der Wyk, A. (1944): Properties of polymer solutions. XVIII. Thermodynamic analysis of binary systems with a chain-shaped component. Helv. Chim. Acta, 27:845-858 (in French).

Muggianu, Y.M., Gambino, M. \& Bros, J.P. (1975): Enthalpies of formation of liquid alloy bismuth-gallium-tin at $723 \mathrm{~K}$. Choice of an analytical representation of integral and partial excess functions of mixing. J. Chim. Phys., 72:83-88.

Mukhopadhyay, B., Basu, S. \& Holdaway, M. (1993): A discussion of Margules-type formulations for multicomponent solutions with a generalised approach. Geochim. Cosmochim. Acta, 57:277-283.

Neogi, S., Dasgupta, S. \& Fukuoka, M. (1998): High P-T metamorphism, dehydration melting, and generation of migmatites and granites in the higher Himalayan crystalline complex, Sikkim, India. J. Petrol., 39:61-99.

Orye, R.V. \& Prausnitz, J.M. (1965): Thermodynamic properties of binary solutions containing hydrocarbons and polar organic solvents. Trans. Faraday Soc., 61:1338-1346.

Ottonello, G. (1992): Interactions and mixing properties in the $(C 2 / c)$ clinopyroxene quadrilateral. Contrib. Mineral. Petrol., 111:53-60.

Pelton, A.D. \& Blander, M. (1986): Thermodynamic analysis of ordered liquid solutions by a modified quasichemical approach - Applications to silicate slags. Metall. Trans., B, Process Metall., 17:805-815.

Powell, R. (1983): Thermodynamics of complex phases. In Saxena, S.K. (ed.): Advances in physical geochemistry, Vol. 2. Berlin-Heidelberg-New York (N.Y.): Springer-Verlag, 241-266.

Powell, R. (1987): Darken's quadratic formulation and the thermodynamics of minerals. Am. Mineral., 72:1-11. 
Prausnitz, J.M., Lichtenthaler, R.N. \& de Azevedo, E.G. (1986): Molecular thermodynamics of fluid-phase equilibria. 2nd ed. Englewood Cliffs (N.J.): Prentice-Hall.

Redlich, O. \& Kister, A.T. (1948): Thermodynamics of non-electrolyte solutions, x-y-t relations in a binary system. Ind. Eng. Chem., 40:341-345.

Renon, H. \& Prausnitz, J.M. (1968): Local compositions in thermodynamic excess functions for liquid mixtures. J. Am. Inst. Chem. Eng., 14:135-144.

Sack, R.A. \& Loucks, R.R. (1985): Thermodynamic properties of tetrahedrite-tennantites: Constraints on the independence of the $\mathrm{Ag} \leftrightarrow \mathrm{Ca}, \mathrm{Fe} \leftrightarrow \mathrm{Zn}, \mathrm{Cu} \leftrightarrow \mathrm{Fe}, \mathrm{Ag} \leftrightarrow \mathrm{Sb}$ exchange reactions. Am. Mineral., 71:257-269.

Shibue, Y. (1999): Calculations of fluid-ternary solid solutions equilibria: An application of the Wilson equation to fluid-(Fe,Mn,Mg) TiO 3 equilibria at $600{ }^{\circ} \mathrm{C}$ and 1 kbar. Am. Mineral., 84:1375-1384.

Spear, F.S. (1995): Metamorphic phase equilibria and pressure-temperature-time paths. Washington, D.C.: Mineral. Soc. Am.

Stimpfl, M., Ganguly, J. \& Molin, G. (1999): $\mathrm{Fe}^{2+}-\mathrm{Mg}$ order-disorder in orthopyroxene: equilibrium fractionation between the octahedral sites and thermodynamic analysis. Contrib. Mineral. Petrol., 136:297-309.

Sundman, B. \& Ågren, J. (1981): A regular solution model for phases with several components and sublattices, suitable for computer applications. J. Phys. Chem. Solids, 42:297-301.

Thompson, J.B., Jr. (1967): Thermodynamic properties of simple solutions. In Abelson, P.H. (ed.): Researches in geochemistry, Vol. 2. New York (N.Y.): Wiley, 340-361.

Toop, G.W. (1965): Predicting ternary activities using binary data. Trans. Am. Inst. Min. Eng., 233: 850-855.

Truskinovskiy, L.M., Sigalovskaya, Yu.I., Senderov, E.E. \& Urusov, V.S. (1987): A general quasi-chemical model of mineral disordering. Geokhimiya, 11:1511-1526.

Vinograd, V.L. (2001): Configurational entropy of binary silicate solid solutions. In Geiger, C.A. (ed.): Solid solutions in silicate and oxide systems /EMU Notes Mineral., 3/. Budapest: Eötvös Univ. Press, 303-346.

Wilson, G.M. (1964): Vapor-liquid equilibrium. XI. A new expression for the excess free energy of mixing. J. Am. Chem. Soc., 86:127-130.

Wohl, K. (1946): Thermodynamic evaluation of binary and ternary liquid systems. Trans. Am. Inst. Chem. Eng., 42:215-249.

Wohl, K. (1953): Thermodynamic evaluation of binary and ternary liquid systems. Chem. Eng. Prog., 49:218-221.

Wood, B.J. \& Nicholls, J. (1978): The thermodynamic properties of reciprocal solid solutions. Contrib. Mineral Petrol., 66:389-400. 